\title{
Familias y Televisión: una reconstrucción sistémica
}

\author{
Luis Alfonso Guadarrama Rico \\ Centro de Investigación y Estudios Avanzados en Ciencias \\ Politicas y Administración Pública, UAEM
}

\section{Introducción}

La recepción televisiva, a partir de la década de los ochenta y lo que va de la presente, ha sido objeto de diversos replanteamientos teóricos y metodológicos que han contribuido a mejorar la comprensión de este proceso de comunicación. ${ }^{1}$ Este reporte de investigación pretende constituir un eslabón más en esta cadena y, con él, he tratado de acercarme a la recepción televisiva en la familia desde la perspectiva sistémica, por considerar que este enfoque puede servir para explicar dicho fenómeno.

En la primera parte del documento refiero los principales hallazgos que varios autores han hecho sobre ángulos distintos de la recepción televisiva. Después, planteo una serie de inquietudes que me han generado los estudios que a la fecha he revisado y, con base en ellas, presento los resultados de un estudio llevado a cabo en tres familias.

\section{Antecedentes}

Trabajos recientes han puesto en claro que la televisión se encuentra inscrita en la vida doméstica y que por lo tanto "ver televisión" exige cierta compatibilidad con los ritmos de actividad de sus miembros y quizá constituye el eje de gravitación de los intercambios personales.

James Lull, quien sigue una perspectiva basada en reglas, estudia los procedimientos de selección y los patrones de comunicación familiar; encontró que las familias emplean la televisión para evitar comunicarse o conversar a cierta profundidad sobre aspectos particulares, cuestión que hace pensar en este medio masivo como un regulador de la comunicación entre los miembros de las familias. (Lull, 1980: 197-200) Irene Goodman -quien trabaja desde una perspectiva sistémica- señala que cuando la televisión constituye

1 Ver los trabajos de Goodman, 1983; Lull, 1992; Orozco, 1992; Comejo, 1994; Barrios, 1992; Renero, 1992; Segura, 1992. 
un medio empleado frecuentemente para evitar o interrumpir la comunicación en la familia, ha de interpretarse como un síntoma de desequilibrio en el sistema familiar global y no como una conducta social aislada, dado que "ver televisión" y la comunicación interpersonal, forman parte de una dinámica interaccional incrustada en la cotidianidad de la propia familia. (Goodman, 1983: 405-424)

Cuando Irene Goodman señala "desequilibrio en el sistema familiar”, me parece que ofrece una pista muy interesante acerca de la recepción televisiva y de ésta unidad de análisis que es la familia, pues en tanto sistema la integran individuos, (elementos) que desempeñan funciones distintas, roles, rutinas y generan un clima o dinámica interaccional que podría prefigurar las formas y matices en los que se desarrollan los momentos de "ver televisión".

Por su parte, Morley nos presenta un análisis de las prácticas de expectación genéricamente determinadas y de las dinámicas familiares, a través de las cuales ofrece una interpretación del contexto familiar y cómo éste debe ser empleado para buscar entender las formas de ver televisión. (Morley, 1986) En el marco del mismo interés, Gray encuentra que en los matrimonios de estructura patriarcal, los hombres suelen sentarse a ver su programa favorito de televisión, mientras que las mujeres no pueden hacerlo, en parte, porque los miembros masculinos toman precedencia y, también, porque la atención de las mujeres se divide entre la pantalla y las peticiones de los esposos e hijos. (Gray, 1987)

Un primer aspecto que podríamos derivar es que las costumbres de la familia y las relaciones que se gestan y suceden al interior de esta unidad básica, parecen prefigurar los hábitos televisivos. Autores como Furó mencionan que el papel que desempeñan los padres de familia y los hermanos mayores, abren o cierran el abanico de temas programáticos a los que puede tener acceso un infante, ${ }^{2}$ es decir, Furó identifica como variable independiente del consumo programático el papel que desempeñan los miembros de la familia mayores, respecto a los menores.

Leoncio Barrios, realizó un trabajo etnográfico con el propósito de analizar la relación entre la televisión y la comunicación en el contexto de la familia. Parte de sus resultados apuntan que "los problemas de comunicación familiar suelen ser multicausados por factores tanto intra como extrafamiliares". (Barrios, 1992:71)

En otro estudio, Martha Renero, pone en el centro de su atención a la madre de familia como" el agente social de más peso en el ámbito doméstico y por ende, la interacción madre-hijos es el proceso más influyente en la 
recepción televisiva de estos últimos”. (Renero, 1992: 33) La autora busca analizar cómo la mediación materna es capaz de crear, re-crear y articular diferentes prácticas de comunicación encaminadas a la supervivencia cultural de la institución familiar y cómo esta mediación ayuda a explicar las apropiaciones y aprendizajes que los niños derivan de su interrelación con la programación televisiva.

En un reporte de investigación Nora Segura analiza los resultados de un estudio de campo en el que aplicó un cuestionario a 152 mujeres dedicadas al hogar. La autora concluye que "la centralidad de la mujer en el hogar la convertía en la televidente más propensa a lo largo del día y probablemente la persona mejor informada sobre los hábitos y rutinas de otros miembros". (Segura, 1992: 180) Asimismo, señala que "Las formas de consumo televisivo y las relaciones conflictivas o no con otras actividades y hábitos de la familia, dependen, entre otros factores, del grado de diferenciación del espacio habitacional, de la relación entre número de televisores disponibles y número de miembros de la familia, y del grado de incompatibilidad entre actividades y personas". (Segura, 1992: 188)

Como podemos apreciar, en estos últimos años, tanto la televisión como el televidente no solo han sido objeto de integración, para tratar de dar cuenta de un proceso interactivo, sino que además "ver televisión" se ha contextualizado cultural, socialmente y en el ámbito cotidiano de su unidad básica: la familia. Los estudios referidos -en mi opinión- han explorado tanto las formas de interacción, como los papeles o roles que algunos miembros de la familia dejan ver o connotan en el proceso de recepción, sin embargo, parece haber un gran ausente en una buena parte de las investigaciones encontradas hasta ahora: la familia.

Poco se ha dicho sobre las características de esta unidad básica en la que ocurre la recepción televisiva, y sí -en cambio- se perfilan rutinas, formas de consumo, centralidad de la madre; interacción madre-hijos; consumo de programas según géneros, etc. Pero ¿de qué tipo de familias se trata? Desde luego, se dan indicadores acerca del nivel socioeconómico; de la urbanidad o ruralidad de las familias, o bien se habla de grados de permisividad vigente en los padres, pero ¿la estructura de la familia? ¿La dinámica que le constituye y da cuerpo? ¿La edad de los padres y por lo tanto la generación de familia de la que se habla? ¿El número de miembros que originalmente componían a la familia y los que en el momento de la investigación la componen? ¿Las ocupaciones de cada miembro de la familia? ¿Su edad y el marco de sus intereses? Se da por sentado que es suficiente con decir que se trata de una familia urbana o rural, de nivel socioeconómico alto, medio o bajo, independientemente de su estructura 
y dinámica. Como indica Andrée Michel, "no puede hablarse teóricamente de la familia en general sino únicamente de tipos de familia...”. (Michel, 1974: 7)

¿Cómo construir y dar cuenta de estos cimientos y pisos del edificio, para después arribar, nuevamente, a la centralidad de la recepción televisiva en y desde la familia? Considero que una posibilidad puede ser construida utilizando el aparato conceptual sistémico. En el campo de la psicología, varios autores, ${ }^{3}$ precisamente desde esta perspectiva, han estudiado los procesos de organización y modalidades de relación interpersonal, estableciendo como punto de partida la clarificación de la estructura y tipología de la familia de la que se trata. En las siguientes páginas se presentan los elementos conceptuales en los que se apoyó el presente estudio.

\section{Marco Conceptual}

\subsection{La familia, un sistema}

De acuerdo con Cusinato, un sistema se puede definir como cualquier entidad abstracta o concreta, constituida por partes interdependientes. Los organismos vivos se conceptúan como sistemas abiertos, debido a que intercambian material con el ambiente que les rodea. Así, el estado normal de un organismo vivo o sistema abierto no es el equilibrio. Debido a ello, dentro de la concepción sistémica se presta atención al comportamiento interactivo y a los procesos de autorregulación y transformación del sistema familiar como conjunto compuesto por individuos. (Cusinato, 1992: 228- 237)

En términos formales y apoyados en Giddens, la familia podría ser definida como "un grupo de personas directamente ligadas por nexos de parentesco, cuyos miembros adultos asumen la responsabilidad del cuidado de los hijos". (Giddens, 1991: 415) Los lazos de parentesco constituyen nexos entre individuos, establecidos vía el matrimonio o la unión libre que ligan genealógicamente a los consanguíneos. (madres, padres, descendientes, tíos, abuelos, etc.) Para los propósitos de este trabajo, tal definición sería insuficiente.

La familia, vista desde el enfoque sistémico, es un sistema abierto; entidad dinámica que está en proceso de cambio continuo, lo mismo que sus contextos sociales, es decir, recibe y envía descargas de y desde el medio extra familiar o, si se quiere, recibe presión del exterior originada en los naturales requerimientos que le demanda el contexto socio- histórico para acomodarse a las instituciones sociales significativas que influyen sobre los miembros familiares. Al mismo tiempo, está sometida a presión interna originada por la

3 Ver Andolfi, 1997; Hoffman, 1987; Cusinato, 1992; Minuchin, 1994. 
evolución de sus propios miembros y subsistemas. Por ello, este grupo relacional primario siempre ha sufrido cambios que guardan cierta correspondencia con las modificaciones que suceden en la sociedad a la que pertenece y de la cual forma parte. Sus funciones, en lo interno, son la protección psicosocial de sus miembros y, en lo externo, como lo marca Minuchin, "la acomodación a una cultura y a la transmisión de esa cultura”. (Minuchin, 1994: 78)

Esta unidad ha de ser vista como totalidad en tanto compuesta por formas de vida diferentes, donde cada parte cumple su papel, pero, como lo indican Munuchin y Fischsman, "el todo constituye un organismo de múltiples individuos, que en sí mismos son una forma de vida”. (Minuchin y Fischsman, 1993: 26) Este organismo familiar, procede según reglas preexistentes pero eventualmente pueden suceder cambios que demandan transformaciones, debido a que las personas que conforman a la familia, en cada una de sus interacciones, solo manifiestan parte de sus repertorios comportamentales. Estas suelen ser múltiples y acaso insospechadas, pero emergen solo algunas debido a las características y condiciones que ofrece la estructura del contexto. Cuando los contextos sufren modificaciones, es decir, se amplían o surgen quiebres es factible que se presenten nuevas interacciones. Las personas se acomodan en forma de caleidoscopio para lograr la reciprocidad que posibilita las relaciones humanas. Por ejemplo, un cambio en la posición jerárquica en el seno de la familia produce un cambio en cada uno de sus miembros y en lo que se considera permitido en las interacciones entre ellos.

En razón de estas características, es indispensable entender que la familia es un sistema social en transformación que presenta muchas fases en su evolución natural a lo largo del tiempo y que en esa dinámica, la familia y por ende sus miembros buscan adaptarse a través de la negociación de nuevas reglas familiares, en las que aparecen nuevos subsistemas y se trazan también nuevas líneas de diferenciación, no sin distintos niveles de conflicto. De esto se desprende que a la familia es necesario conceptualizarla e investigarla como un sistema que posee una estructura en movimiento.

\subsection{Estructura familiar}

Minuchin ${ }^{4}$ define el concepto de estructura de la siguiente manera: "es el conjunto invisible de demandas funcionales que organizan los modos en que

4 Minuchin es uno de los autores que dentro de la terapia familiar con enfoque sistémico ha proporcionado, para los propósitos del presente trabajo, elementos conceptuales para entender y analizar a la familia como sistema 
interactúan los miembros de una familia. Una familia es un sistema que opera a través de pautas transaccionales". (Minuchin, 1993:86) Las transacciones reiteradas fijan pautas acerca de qué manera, cuándo y con quién relacionarse, y estas pautas apuntalan el sistema. Por ejemplo, cuando una madre le dice a su hijo que no vea determinado programa y éste apaga la televisión, esta interacción define quién es ella en relación con él y quién es él en relación con ella, en esos términos constituyen una pauta transaccional.

\subsection{Sistemas de coacción y subsistemas}

Las pautas transaccionales regulan la conducta de los miembros de la familia y son mantenidas por dos sistemas de coacción. El primero es genérico e implica las reglas que gobiernan la organización familiar. Por ejemplo, existe una jerarquía de poder en la que los padres y los hijos poseen niveles de autoridad diferentes. A este respecto, González señala que dentro de las familias "se conforman diferentes tipos de redes de distribución y ejercicio del poder”. (González, 1993: 330) Y que este ofrece una visión configuracional, primero y luego, móvil de las relaciones ternarias del poder. Por ello, destaca González, "Una madre puede dominar ciertos tópicos o escenarios familiares; pero ante otras situaciones someterse a la "autoridad" o al dominio de otro miembro mejor colocado”. (González, 1993: 330) También existe una complementariedad de las funciones, en la que el marido y la esposa aceptan la interdependencia y operan como un equipo, por dispareja que estén distribuidas las responsabilidades.

El segundo sistema de coacción es idiosincrático, e implica las expectativas mutuas de los diversos miembros de la familia. El origen de estas expectativas se encuentra sepultado por años de negociaciones explícitas e implícitas entre los miembros de la familia, relacionadas a menudo con los pequeños acontecimientos diarios. De este modo, el sistema se mantiene a sí mismo. Ofrece resistencias al cambio más allá de cierto nivel y conserva las pautas preferidas durante tanto tiempo como puede hacerlo.

El sistema familiar se diferencia y desempeña sus funciones a través de sus subsistemas. Los individuos son subsistemas en el interior de una familia. Las díadas como la de marido-mujer o madre-hijo. (a), hermano(a)-hermano(a) pueden ser, respectiva y diferencialmente, subsistemas conyugal, parental o fraterno. Los subsistemas pueden ser formados por generación, sexo, interés o función. Cada individuo pertenece a diferentes subsistemas en los que posee diferentes niveles de poder y en los que aprende habilidades diferenciadas. 


\subsection{Subsistemas y límites}

Los límites de un subsistema están constituidos por las reglas que definen quiénes participan, y de qué manera. La función de los límites reside en proteger la diferenciación del sistema

En términos humanos, aglutinamiento y desligamiento se refieren a un estilo transaccional, o de preferencia por un tipo de interacción, no a una diferencia cualitativa entre lo funcional y los disfuncional. La mayor parte de las familias poseen subsistemas aglutinado $s$ y desligados.

La madre y los niños más pequeños pueden aglutinarse hasta un punto tal como para determinar que el padre sea periférico, mientras el padre asume una posición más comprometida con los hijos mayores. Sin embargo, un subsistema padre-hijo puede tender hacia el desligamiento a medida que los niños crecen y, finalmente, comienzan a separarse de la familia.

\section{Metodología}

Con base en el marco expuesto y las categorías descritas, se procedió a llevar a cabo el estudio basado en entrevistas cualitativas en profundidad, ${ }^{5}$ dirigidas a uno de los miembros de la familia, quienes se constituyeron en los informantes de sus propios escenarios. Enseguida se explica el objetivo y la estrategia metodológica aplicada.

\subsection{Objetivo}

El propósito de este reporte es ofrecer un primer acercamiento al estudio de la estructura y dinámica familiar, como posibles prefiguradoras de las pautas de interacción con la televisión, para tratar de explicar cómo interactúan y se mueven estos elementos del sistema familiar en escenas en las que está implicada tácita o virtualmente la televisión.

5 Taylor y Bogdan hacen referencia a tres tipos de entrevistas en profundidad. Aquí se empleó el segundo tipo, dirigido "al aprendizaje sobre acontecimientos y actividades que no se pueden observar directamente. En este tipo de entrevistas nuestros interlocutores son informantes en el más verdadero sentido de la palabra. Actúan como observadores del investigador, son sus ojos y oídos en el campo. En tanto informantes, su rol no consiste simplemente en revelar sus propios modos de ver, sino que deben describir lo que sucede y el modo en que otras personas lo perciben”. (Taylor y Bogdan, 1984: 103) 


\subsection{Universo de Estudio}

Las familias analizadas en este documento son tres, dos de ellas con domicilio en la Ciudad de Toluca, Estado de México y una más en el Municipio de Tizayuca, Estado de Hidalgo. La razón por la que fueron elegidas estas familias se debió a las características que presentaban en cuanto a su estructura y dinámica familiar. El estudio completo incluye un total de diez familias con estructuras diferentes pero manteniendo como característica común que entre sus miembros existe uno que estudia la Licenciatura en Comunicación en la Universidad Autónoma del Estado de México.

\subsection{Procedimiento de recolección de información familiar}

Integrada la lista de los 10 estudiantes que tomaron parte en el estudio, a cada uno de ellos les fue solicitada la información que a continuación se refiere, indicando a cada uno que -para efectos del reporte de investigación- asignaran a sus respectivas familias, nombres y apellidos distintos de los reales.

1. Genograma ${ }^{6}$ actual

2. Breve curriculum de cada miembro

3. Croquis de su casa-habitación, especificando domicilio, distribución de áreas y tamaño de cada una.

4. Con base en el genograma, se pidió que el estudiante valorara el tipo de interacción que predominaba entre cada uno de los miembros de la familia y que lo representara de acuerdo con la simbología empleada por la Task Force of the North American Primar Care Research.

5. De cada uno de los miembros de familia, se especificaron las actividades generales y horarios de cada una, con el propósito de tener un punto de partida acerca del marco de las rutinas de los elementos que constituían a cada familia.

6. En una copia del croquis de la casa-habitación, se solicitó una lista del equipo doméstico con que contaba cada familia; su estado (en uso o descompuesto) y en qué área de la casa se encontraba ubicado usualmente.

6 De acuerdo con McGoldrick y Gerson, el genograma es “un formato para dibujar un árbol familiar que registra información sobre los miembros de una familia y sus relaciones.... (McGoldrick y Gerson, 1993: 17) Es decir, constituyen representaciones gráficas de una familia y permiten explorar su estructura y, digamos, "poner al día” el cuadro familiar. Aunque los genogramas en terapia familiar son empleados fundamentalmente para estudiar árboles familiares de por lo menos tres generaciones, ello no impide su aplicación en otras áreas del conocimiento. 
Esta tarea fue complementada con una tabla de doble entrada en la que se especificó el tipo de equipo (radio grabadora, televisión, videocasetera, radio, teléfono, estéreo, computadora, dispositivo para videojuegos, horno de microondas, lavadora, etc.) marca, características, ubicación y, en su caso, si es era de uso exclusivo de algún miembro de la familia.

7. Para el caso de la televisión, se requirió el detallamiento del sistema de recepción con que contaban, la fecha de contratación y los canales que captaba dicho sistema.

8. También con base en los genogramas fue solicitado a cada estudiante que observara y registrara las actividades que usualmente realizaba cada uno de los miembros de su familia. Que destacara el rango de horario en el que veía televisión, el o los programas que solía mirar y que acotara si era actividad que realizaba solo o en compañía de otro u otros miembros familiares o extrafamiliares.

\subsection{Periodo de observación}

El acopio de información fue realizado del 20 de octubre de 1994 al 15 de febrero de 1995. De esta manera, se tuvo oportunidad de contar con elementos para analizar posibles cambios en las rutinas y pautas de interacción, como consecuencia del periodo vacacional decembrino, aspecto que por ahora dejamos pendiente para un reporte más amplio.

\section{Resultados}

En primer término, presentamos los genogramas de cada una de las familias y, después, se procede a integrar el análisis de la información, con énfasis en las pautas de interacción entre los miembros de la familia y entre éstos y la televisión.

\subsection{Las familias}

Cuando se escribe acerca del binomio televisión-familia, poco se sabe en detalle de las familias que fueron investigadas. Aquí planteo la necesidad de contar con información fundamental acerca de la estructura y dinámica que privan en los elementos que constituyen a la familia, así como datos del equipamiento cultural doméstico, las características espaciales de la casahabitación y, desde luego, las rutinas de cada uno de los miembros que la integran. Este tipo de información es valiosa porque permite conocer parte 
de contexto de cada familia y contribuye a dar sentido a las observaciones. De otra manera, se corre el riesgo de llegar a conclusiones erróneas o sesgadas, debidas a la falta de datos básicos de las familias que se estudian.

\subsubsection{La Familia Betancourt Junco}

En el genograma de la página siguiente, se puede apreciar que la estructura familiar está constituida por cuatro miembros. La pareja está casada desde el año de 1972, tienen dos hijos, una mujer y un varón, de 21 y 20 años, respectivamente.

De arriba hacia abajo y de izquierda a derecha, la información sobre la familia nos reporta lo siguiente: el padre tiene 48 años de edad, cursó hasta el segundo grado de medicina, trabaja como empleado de las 9:00 a las 18.00 hrs.; la madre, tiene 43 años, concluyó sus estudios de comercio. (Nivel técnico profesional), labora como empleada. (Cajera) de las 9:00 a las 18:00 hrs.; Miriam, la hija mayor, tiene 21 anos y cursa el 50 semestre de la Licenciatura en Comunicación, en un horario de 7:00 a 13:00 hrs., realiza su servicio social de las 16:00 alas 20.00 hrs.; César, el hijo menor, tiene 20 años de edad, cursa el 3er semestre de la Licenciatura en Informática, de las 15:00 a las 21:00 horas. (Ver anexo 1)

La familia vive en la ciudad de Toluca, en una colonia de nivel socioeconómico medio. Habitan en una casa de $112 \mathrm{~m} 2$, distribuidos en tres recámaras, sala, comedor, cocina, baño, patio de servicio y estacionamiento. Las rutinas de cada uno de los miembros están organizadas alrededor de sus propias necesidades y ocupaciones. En esta estructura familiar, el sistema de coacción está conformado por las actividades laborales de los padres y el estudio de los hijos. El sub sistema conyugal parece estar caracterizado por la complementariedad y acomodación en tomo al sostenimiento de la familia; a partir de la 18:00 hrs. Los padres comparten la hora de la comida y, de allí en adelante, el resto del tiempo permanecen en su casa. Cada uno de los hijos constituye un sub sistema, configurado por sus responsabilidades de estudio.

1 y2 De acuerdo con la valoración de Miriam, el clima de interacción dominante en su familia es buena y, en particular, calificó como muy unido entre ella, su hermano y su madre.

Disponen de tres televisores a color, uno ubicado en la sala de la casa; otro en la recámara de Miriam y el tercero en la recámara de Sajid y Martha. La videocasetera y uno de los estéreos están junto al televisor de la sala. Miriam tiene en su habitación una radio grabadora y César, en su recámara, un estéreo. La familia cuenta con teléfono inalámbrico. 
Respecto a la oferta de canales disponibles, asciende a 16. Desde 1986 la familia contrató el Sistema de Televisión por Cable, ${ }^{7}$ mismo que les permite recibir parte de una imagen más nítida de los canales de Televisa e Imevisión, una oferta de 10 canales. (Ver anexo 2)

Fig. No. 1

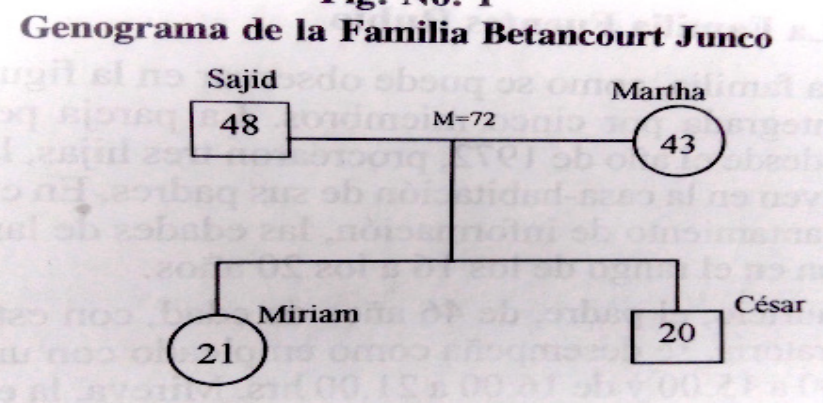

Fig. No. 2

Genograma de la Dinámica Relacional

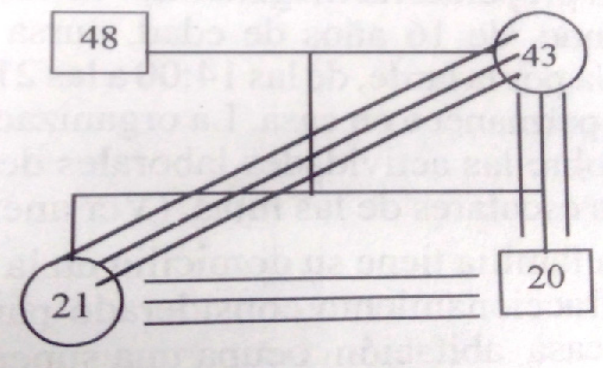

7 TV-Comunal de México S.A. de C.V., es una empresa privada que desde la mitad de la década de los setentas empezó a ofrecer sus servicios de televisión por cable en la Ciudad de Toluca. Las señales que actualmente ofrece a sus suscriptores las subcontrata a Multivisión. A la fecha ha extendido su cobertura en los municipios del Valle de Toluca. 


\subsubsection{La Familia Fuentes Rubio}

Esta familia, como se puede observar en la figura No. 3, está integrada por cinco miembros. La pareja permanece unida desde el año de 1972, procrearon tres hijas, las cuales aún viven en la casa-habitación de sus padres. En el período de levantamiento de información, las edades de las hijas se movían en el rango de los 16 a los 20 años.

Mauricio, el padre, de 46 años de edad, con estudios de preparatoria, se desempeña como empleado con un horario de 9:00 a 15:00 y de 16:00 a21.00 hrs. Mireya, la esposa de Mauricio y madre de las tres hijas, tenía 44 años de edad, con estudios de preparatoria, tiene empleo como secretaria con un horario de 9:00 a 15:30 hrs. Libia, la primera hija en orden de nacimiento, con 20 años de edad, cursa la licencia- tura en Comunicación de 7:00 a 13:00 hrs., de lunes a viernes; continua con clases de Inglés hasta las 15:00 y, los martes y jueves, de 17:00 a 19:00 hrs. asiste al curso de Francés. Melisa, la segunda hija, de 17 años de edad, asiste a la escuela preparatoria magisterial ${ }^{8}$ de las 8.00 a las 14:00 horas. Ivonne, de 16 años de edad, cursa sus estudios de preparatoria por la tarde, de las 14:00 a las 21: 00 hrs., durante la mañana permanece en casa. La organización familiar está asentada sobre las actividades laborales de los padres y las actividades escolares de las hijas. (Ver anexo 3)

3y4Esta familia tiene su domicilio en la Ciudad de Toluca, en un fraccionamiento considerado para gente de clase media. Su casa habitación ocupa una superficie de 104

metros cuadrados. La distribución del espacio incluye en la planta baja, estacionamiento, sala, comedor, cocina, patio y cuarto de lavado y planchado; en la planta alta se encuentran tres habitaciones y baño completo. La interacción dominante en la familia, de acuerdo con la opinión de Libia, fue calificada de muy unida entre las tres hermanas, con regula- res conflictos entre el padre y Libia y, entre éste e Ivonne. (Ver figura No. 4)

8 La preparatoria magisterial, a diferencia de la universitaria, orienta su plan de estudios a la Licenciatura en Educación. También se le conoce como bachillerato pedagógico. 
Figura No. 3

\section{Genograma de la Familia Fuentes Rubio}

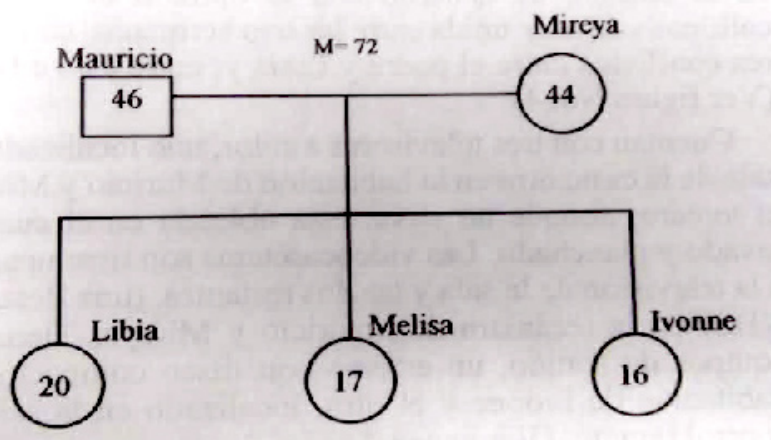

Fig. No. 4

Genograma de la Dinámica Relacional

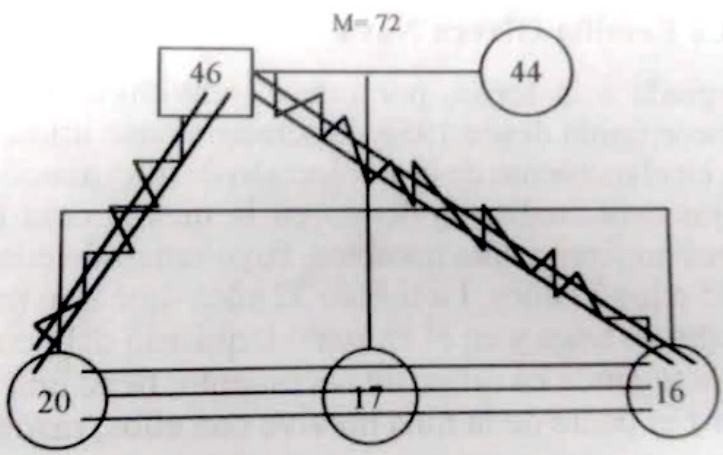


Cuentan con tres televisores a color, uno localizado en la sala de la casa; otro en la habitación de Mauricio y Mireya y, el tercero, aunque no sirve, está ubicado en el cuarto de lavado y planchado. Las videocaseteras son tres: una, junto a la televisión de la sala y las dos restantes. (Una Beta y otra VHS) en la recámara de Mauricio y Mireya. Tienen dos equipos de sonido, un estéreo con disco compacto en la habitación de Ivonne y el otro, localizado en la sala, con control remoto. (Ver anexo 4)

Los dos televisores que funcionan (uno en la sala y el otro en la recámara de Mauricio y Mireya) tienen, a diferencia de la familia Betancourt Junco, una oferta de 24 canales. La razón es que durante el mes de mayo y noviembre de 1994, la familia Fuentes Rubio contrató el servicio adicional de canales complementarios para cada uno de los televisores en operación.

\subsubsection{La Familia Olvera Nava}

Integrada a la fecha, por nueve individuos. La pareja permanece unida desde 1958. Procrearon once hijos, de los cuales, en el momento de la recolección de información, solo seis hijos continuaban viviendo en la misma casa-habitación; tres mujeres y tres hombres, cuyo rango de edades va de los 15 a los 32 años. La hija de 32 años -que se representa en la segunda línea y en el extremo izquierdo del geneograma- es la segunda en orden de nacimiento; tiene una hija de 12 años y el padre de la niña no vive con ellos, razón por la que en el genograma se representa con línea discontinua la usencia del padre. (Ver siguiente figura No. 5)

Para cada miembro de la familia, la información adicional es como sigue: Miguel, el padre, tiene 55 años, estudió hasta el sexto de primaria, se desempeña como contratista y trabaja de las 8:00 a las 18:00 horas. Dolores, la madre, tiene 52 años, concluyó sus estudios de primaria y se dedica a las labores domésticas. Griselda tiene 32 años, estudió la secundaria, se desempeña como obrera, con un horario vespertino que va de las 14:00 a las 22:00 hrs. Mariana, de 23 años, estudió la carrera de técnica en diseño de modas; los días miércoles, jueves y sábados los dedica a la costura, actividad que realiza en la casa donde vive, de las 8:00 a las 14:00 hrs., en la casa donde vive y el resto de la semana elabora postres para venderlos en la localidad. Valeria, de 20 años, estudia la licenciatura en la universidad, ocupación que le absorbe de las 7:00 a las 13:00 horas de lunes a vienes. Humberto, de 18 años de edad, cursa el cuarto semestre de contador técnico, en un horario de 7:00 a 14.00 hrs. Gerardo, de 17 años de edad, estudió el nivel medio básico, no labora actualmente. Guillermo, de 15 años, estudia el último año de secundaria, ac- 
tividad que le ocupa le las 7:00 a las 13:00 hrs. Finalmente, Paola, la hija de Griselda, tiene 12 años, cursa el primero de secundaria, con un horario de 8:00 a 13:00 hrs, de 13:00 a 15:00 continúa con clases de gimnasia en la misma escuela, pero son sesiones pagadas e independientes del currículo de su educación media básica; los sábados y domingos, de las $7: 00$ las 15 :00 hrs., Paola trabaja como ayudante en un puesto de venta de ropa que se instala en el tianguis de Tizayuca. Ver anexo 5)

Esta familia tiene su domicilio en el municipio de Tizayuca, Hidalgo. Habitan una casa de $154 \mathrm{~m}$, con tres recámaras, estancia, comedor, cocina, baño y patio de servicio. En general, la rutina familiar inicia a las 6:00 de la mañana. El eje desencadenador de laś rutinas de cinco miembros de la familia está constituido por las ocupaciones que tiene el padre como contratista, arrendador de material para la construcción y la producción pecuaria en pequeña escala.

Estas actividades parecen conformar el sistema de coacción de la organización familiar. No obstante, dos elementos de la familia presentan una clara diferenciación con respecto al sistema de coacción dominante. Grisel$\mathrm{da}$, en tanto tiene un trabajo remunerado fuera de casa y es madre de Paola, ha desarrollado una rutina distinta, y ha generado en el interior del sistema familiar, un sub sistema parental con Paola, aun- que debido a la organización de la rutina de cada una, se puede apreciar que el estilo transaccional de aglutinamiento se manifiesta durante los fines de semana, los días de asueto y los periodos vacacionales. Valeria, por su parte, constituye otro subsistema, instaurado por su estancia, de lunes a viernes, en la Ciudad de Toluca, para realizar sus estudios de licenciatura y su arribo a la casa de su familia durante los fines de semana, le permite trazar una rutina distinta de los demás.

Valeria, al opinar sobre el clima de interacción dominante en su familia, lo calificó como bueno, aunque destacó interacciones conflictivas entre Griselda y su madre; entre Griselda y Valeria; entre Mariana y Humberto y entre Humberto y su madre. (Ver figura No. 6)

Valeria consideró que se mantiene una relación muy unida entre Gerardo y Guillermo y, de ambos para su con padre. Por su parte, Paola, la hija de Griselda y Arturo, como se puede notar en el genograma ya trazado arriba, parece constituir un eje de interacciones mutuamente positivas, que van de unidas a muy unidas con respecto a sus tías, tíos y con su madre.

Los Olvera Nava, disponen de tres televisores, dos a color y uno blanco y negro. Uno de los televisores a color está localizado en la estancia de la casahabitación, junto con una videocasetera. El otro televisor, un estéreo clásico y una radiograbadora con disco compacto, se encuentran ubicados en la recá- 
mara de Miguel y Dolores. (los padres) El otro aparato es un radio-televisor blanco y negro, dispuesto en la habitación que comparten Humberto, Gerardo y Guillermo. La radiograbadora clásica está ubicada en la recámara que comparten Paola, Griselda, Mariana y Valeria. (Ver anexo 6)

En contraste con las dos familias documentadas anteriormente, la oferta de canales con que cuenta la familia Olvera Nava es de ocho canales. Es importante aclarar que en Tizayuca aún no llega el sistema de televisión por cable, aunque hay varias familias de la localidad que han optado por adquirir antena parabólica, para disponer de mayor oferta de canales.

Figura No. 5

Genograma de la Familia Olvera Nava

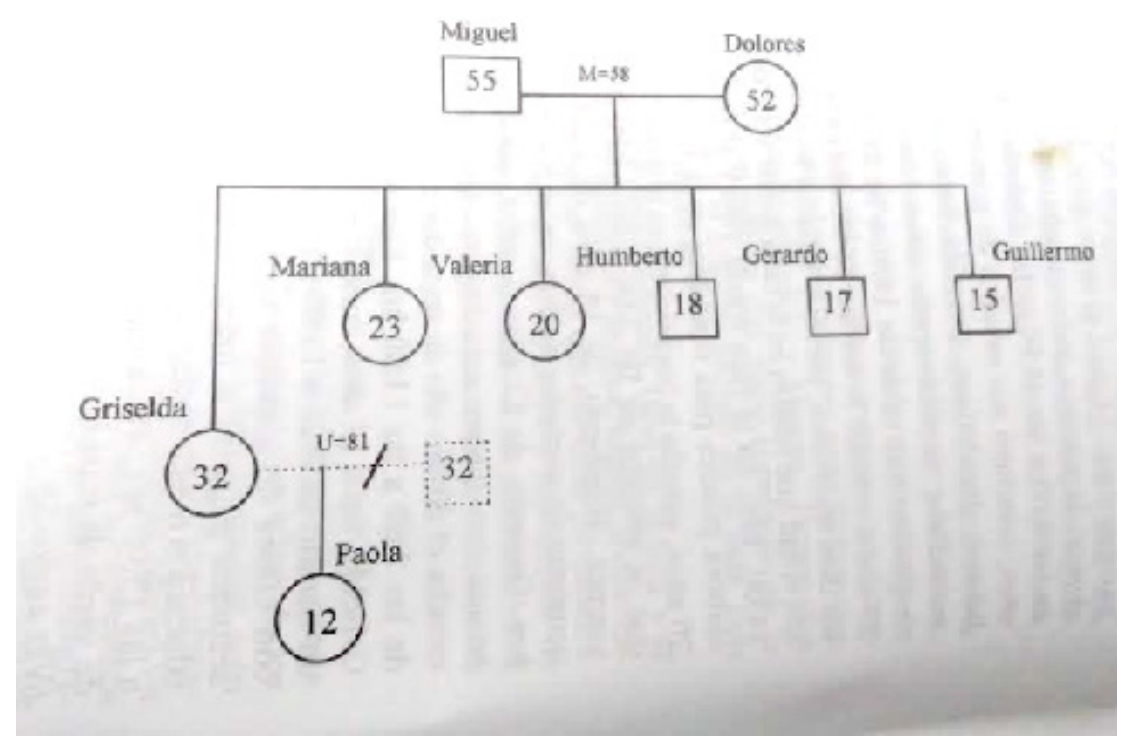


Fig. No. 6

Genograma de la Dinámica Relacional

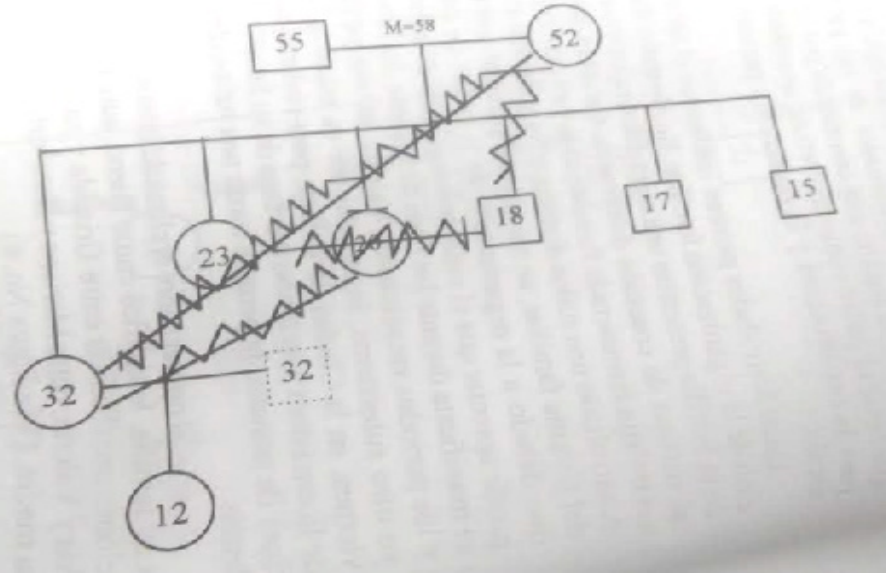

Fig. No. 7

Genograma de la Dinámica Relacional

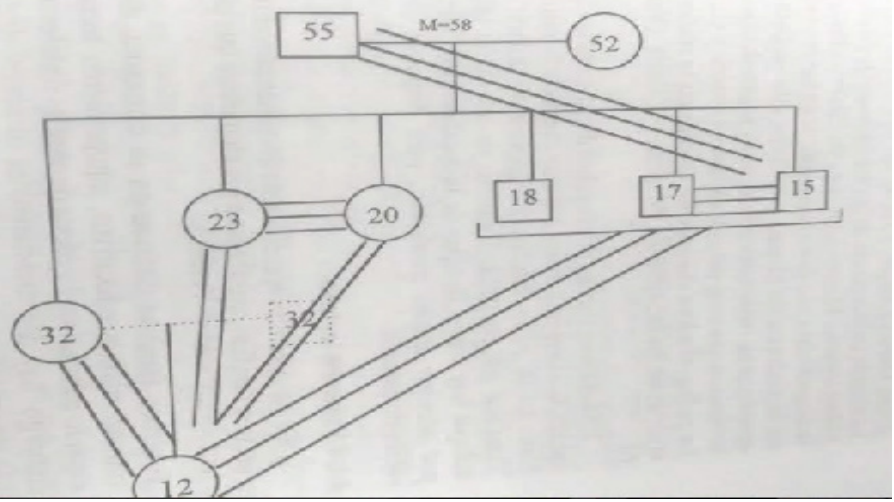




\subsubsection{Primera lectura}

¿Qué nos permite apreciar esta documentación realizada en las tres familias, conforme a los elementos que por ahora se han identificado? Veamos.

i) Tenemos familias distintas en su estructura, dinámica, rutinas, niveles educativos, equipamiento tecnológico, espacio habitacional y oferta de canales de televisión. Sin embargo, hay dos características comunes: disponen de más de un televisor; cuentan con grabadoras y videocasetera; este tipo de tecnología, independientemente del medio rural o urbano en el que se encuentran, constituye el equipamiento cultural que ha filtrado y configurado el espacio doméstico que habitan los miembros de cada familia.

ii) Las dos familias de la ciudad de Toluca, comparativamente con la de Tizayuca, Estado de Hidalgo, disponen menor espacio habitacional pero de un mayor número áreas funcionales diferenciadas. En correspondencia con la disposición de más áreas, cada uno de los hijos de las dos familias urbanas cuenta con un espacio privado unipersonal, en tanto que los del medio rural comparten el espacio con los subsistemas fraternos, diferenciados por género.

iii) Los hijos de las dos familias urbanas, durante el periodo de acopio de información, estaban dedicados -prácticamente- a las actividades de estudio, mientras que algunos hijos de la familia del medio rural (independientemente del género) debían articular sus actividades de estudio con responsabilidades asignadas por el padre de familia relacionadas directamente con la actividad productiva comercial a la que se dedica el progenitor.

iv) En la dinámica familiar documentada, en los Betancourt Junco, privaba un clima muy unido entre los dos hijos y la madre. En la familia Fuentes Rubio, se documentó una relación calificada como muy unidad entre las tres hermanas, pero conflictiva en dirección de la hija mayor y menor con respecto a su padre. Y en la familia Olvera Nava, se anotaron relaciones conflictivas entre algunos de los miembros fraternos y, en dos casos, para con la madre.

Hasta aquí, la interrogante fundamental es ¿cómo interactúan y se mueven estos elementos del sistema familiar en escenas en las que está implicada tácita o virtualmente la televisión? Enseguida se presentan escenas de cada una las familias y posteriormente se ofrece una lectura 


\section{Escenas}

Familia Betancourt Junco

Primera llamada..

Son las 6:00 de la mañana. Sajid y Martha encienden el televisor de su recámara. Miriam hace lo mismo con el suyo; va al baño a ducharse $y$.

Martha: ¿Qué quieres que haga de comer para hoy? Sajid: No sé. Lo que quieras Martha: Conste, luego no reclames

Sajid: Si

Martha: ¿Qué te vas a poner?

Sajid: El pantalón beige, con la camisa azul.

Martha, mientras plancha la ropa que se pondrá Sajid, mira el programa de noticias "Al Despertar", transmitido por el canal 2 de Televisa

Miriam sale del baño, se vestirá y poco antes de las 7:00 saldrá rumbo a la escuela, sin desayunar. Sajid entra a ducharse y Martha, mientras tanto, baja a la cocina a iniciar la preparación de la comida. Los dos televisores continúan encendidos.

Sajid; al salir del baño: Apurate que se nos a hacer tarde. Martha: Ya me voy a bañar

Sajid: ¿Quieres leche caliente?

Martha: Si, calienta el pan y pon la mesa.

Sajid enciende la televisión de la sala y, en espera de Martha, enmedio de los preparativos del desayuno, mira- oye la televisión. Son las 8:30 de la mañana, después del desayuno, Sajid y Martha salen a trabajar.

César despierta hacia las 9:30 de la mañana, enciende el televisor de la recámara de sus papás y busca "More Music", para ver los videos musicales. Quizá desayunará en la sala, con más de "More Music ". Más tarde se duchará, realizará sus tareas en su recámara. Al filo de las 14:00 horas llegará Miriam, su hermana, bajará a comer a la sala para ver-juntos-la televisión,'probablemente el canal 16 de Univisión, que a esa hora transmite telenovelas. César saldrá alrededor de las 14:30 rumbo a la Universidad.

Segunda llamada..

Son las 19:00 horas, de un dia entre semana. Sajid está en la Sala viendo el canal 26 ESPN que transmite exclusivamente programas deportivos. Martha, 
por su parte, está en la recámara de ambos viendo las telenovelas del canal de las estrellas y --entre anuncios-- con el control remoto, da un vistazo a los demás canales.

Son las 21:00 horas del mismo dia entre semana. Salid apaga el televisor de la sala, sube a su recámara y..

Salid: ¿Qué estas viendo?

Martha: (Con el control remoto en mano) Chespirito

Salid: Cámbiale. Eso no me gusta.

Martha: No.

Salid se acuesta y se duerme. Martha continuará viendo la televisión hasta pasadas las 24:00 horas.

\subsubsection{Segunda lectura}

¿Qué tenemos aquí? Un espejo de las rutinas de cada uno de los miembros de la familia, reflejadas en los momentos en los que interactúan con la televisión. También, una muestra del sub sistema constituido por la diáda marido-mujer, que articulan sus actividades, en función de sus responsabilidades laborales y la complementariedad que de ello se deriva. Por la mañana, las formas de interacción televisiva resultan espasmódicas, no solo en el caso de las mujer, como lo refiere Hobson, sino también (en este momento retratado por la escena) por parte de este hombre, que conforma una estructura familiar muy particular. (Hobson, 1982)

César, el hijo menor, visto que ingresa a clases hasta pasadas las 14:00 horas, dispone del espacio y tiempo para elegir qué ver y en qué espacio de la casa. Difícilmente será molestado durante los cinco días de la semana. Su preferencia televisiva ${ }^{9}$ por "More Music" se despliega considerablemente, en su condición de miembro de una familia de cuatro elementos, que disponen de tres aparatos y cuyos padres permanecen hasta pasadas las cinco de la tarde en sus respectivos trabajos.

Más tarde, en la escena de las 19:00 horas, visto que ambos cónyuges han constituido a lo largo del tiempo una regla para la comida; que disponen de más de un aparato de televisión, en espacios diferenciados, cada uno interactúa con el televisor en el canal de su preferencia. No parece haber mu-

9 Un par de anos atrás no encontraríamos esta preferencia en César, por dos razones: no había este tipo de oferta programática en la televisión por cable y, posiblemente su espectro de intereses no incluía el videoclip. 
chas posibilidades de conflicto durante este periodo de registro, debido a que Miriam, por una parte, regresará hasta pasadas las 20:00 horas y cuenta con televisor en su habitación; César, llegará a casa después de las 21:00 horas.

En la escena en la que Sajid sube a su recámara para dormir, le pregunta a su pareja qué está viendo. La selección programática de Martha no es del agrado de Sajid y le indica que le cambie de canal; Martha, con el control remoto en mano, se niega.

Me parece que la escena deja ver un par de aspectos. De un lado es claro que al llegar a la habitación compartida, se gesta un intercambio y posible negociación con lo que cada uno desea ver en la televisión -así sea por un tiempo breve- pero el desacuerdo manifiesto hace que emerjan los sistemas de coacción sembrados con anterioridad. De otro, Martha dice que no cambia de canal ni de programa, y parece materializado el poder de la negación en la posesión del control remoto del televisor, pero posiblemente también tejido con su propia historia como pareja, dada la dinámica relacional que en ellos priva.

\section{Escenas}

Familia Fuentes Rubio

Primera llamada..

Martes por la noche, a eso de las 21: 30 horas. En la sala de la casa están viendo televisión Mireya y sus tres hijas. Tocan la puerta, abre Melissa y..

Mauricio: Ya vine ¿Qué ven?

Melissa: Una película

Mauricio: Cuál

Melisa: Tiro al blanco

Mauricio: ¿En HBO? ¿No ya la habian visto?

Ivonne: $\mathrm{Si}$, pero no importa

Mauricio: Denme chance ¿no? (Toma el control remoto de la televisión y, sin más, le cambia de canal)

Mireya se levanta y va a la cocina a calentar la cena para Mauricio. Libia sube a su recámara a preparar su ropa para el siguiente día. Ivonne sube a la recámara de sus padres a prender la televisión, para continuar viendo la película "Tiro al Blanco". Melisa se queda en la sala, a ver el programa que Mauricio, su padre, eligió. 
A eso de las 22:30 horas, Mauricio apaga el televisor de la sala, se dirige a su recámara; encuentra a Ivonne viendo la película y..

Mauricio: Si quieres ya puedes ir a la sala. Ya me voy a acostar.

Ivonne sale de la recámara y acude a la sala a terminar de ver la pelicula.

$* * *$

Segunda llamada..

Un dia como cualquier otro, entre semana, por ahi de las 19: 30 horas. En la cocina están cenando: Mauricio, Mireya, Melisa e Ivonne.

Libia: Ya vine ¿Todavia no hay luz?

Ivonne: No, todavia no.

Mauricio. ¿Por qué llegaste hasta ahorita?

Libia: Porque me fui a comer a la casa de una amiga, por su cumpleaños.

Mireya-dirigiéndose a Libia-- No te vayas a cambiar, vamos a salir.

Libia: Adónde

Melissa: A la casa de Leticia. (una prima a quien usualmente no acostumbran visitar)

Libia: ¿A su casa? ¿a qué?

Ivonne: A ver la novela. (Imperio de Cristal) porque no sabemos a qué hora va a llegar la luz.

Libia: Ustedes sin la tele no pueden vivir.

Melissa: Tú cállate, sangrona, como te la vives en la calle.. Durante la transmisión de la telenovela "Imperio de Cristal", la familia solía sentarse en la sala a verla, al tiempo que cenaban y conversaban sobre el capitulo en cuestión $y$ diversos temas.

\subsubsection{Tercera lectura}

La primera interpretación que parece saltar o reclamar su lugar es el asunto del "poder", por lo menos en este primer movimiento de la familia, retratado en la primera escena ofrecida. Nótese que es una estructura familiar compuesta por cuatro mujeres y un hombre. Aunque ambos cónyuges tienen un trabajo asalariado, a juzgar por la rutina de trabajo de Mauricio, el padre, se presupone que participa con la mayor parte del ingreso económico para el sostenimiento de la familia, condición que suele marcar pautas de interacción y de distribución de poder diferenciado. 
Mauricio hace una pregunta acerca de lo que están mirando sus tres hijas y su pareja en la televisión de la sala; pero más que una pregunta, constituye el preámbulo, la estrategia para dar entrada al ejercicio del poder. Siguiendo a Michel Foucault "El poder, es aquello que dice no". (Foucault, 1979: 168) Pero el "no" del poder, tiene matices, formas de representación. Así, el poder delimita, rechaza, establece una barrera, censura. y estas relaciones de poder están imbrica- das en los tipos de relación que se fraguan en la familia. (Cfr. Foucault, 1979: 170)

En el caso de la interacción con la televisión, para la escena que nos ocupa, podemos observar cómo hay una estrategia que arranca con la pregunta acerca de qué están viendo y el padre señala (con otra aparente pregunta) que ya la habían visto. La petición que reza Mauricio “Denme chance ¿no?”, desde luego, delimita y establece una barrera que bien puede ser reescrita de mejor manera con un "se acabó su tiempo; llegó el mío". No más televisión en este espacio de la Sala.

Las actividades del resto de los elementos de la estructura familiar se acomodan en forma de caleidoscopio, ante el cambio de la posición jerárquica que privaba en la escena, antes de la llegada del padre. Obsérvese, con el apoyo del genograma de las relaciones interfamiliares, quiénes optan por abandonar la escena televisiva: se trata de Libia e Ivonne, las dos hijas que presentan relaciones conflictivas con su padre; en cambio, Melisa, la segunda hija y quien no parece tener conflictos con la figura paterna, se queda en la escena a ver el programa que Mauricio eligió, constituyendo un estilo transaccional de aglutinamiento. Mireya, como parte complementaria del subsistema conyugal, se desplaza a preparar la cena de su esposo, acción sembrada en años de interacción idiosincrática.

Como se anotó en la documentación de la familia, disponen de dos televisores. Pero el espacio de la sala representa un ámbito en el que se ha de ejercer el poder. Parece constituir el lugar que por sus características funcionales y significados en el interior de la familia, convoca a la reunión de los miembros y, al mismo tiempo, en condiciones específicas, es redefinida su capacidad de arropamiento, en función del poder diferencial que se ejerce.

En un estudio, Hope Jensen y otros, mencionan cómo operan los contextos familiares de la televisión. (Jensen, et. al, 1985) Los autores indican que "cuando un aparato (de televisión) está en un área que es abierta a la mayoría de los miembros de una familia, comúnmente surge la pregunta acerca de quién tiene derecho a estar presente y quién tiene prioridad de elegir lo que van a ver". (Jensen, et. al., 1985: 34) Aquí, para este caso, la respuesta ha sido clara, pero no en términos de la colocación de las sillas o sillones como lo plantean Jensen y sus colaboradores, sino en el tácito ejercicio del poder. 
No obstante, no todo en la familia es poder paterno. Observamos algunos matices importantes en nuestros registros. En la segunda escena, que corresponde a una noche en la que el servicio de luz eléctrica había sido suspendido por varias horas en la zona donde vive la familia Fuentes Rubio, ante la llegada inminente de la hora de transmisión de una telenovela que había convocado, literalmente, a los cinco miembros de la familia, habían acordado ir a la casa de un familiar a ver el capítulo de la telenovela. La decisión fue acordada --fundamentalmente-- por las mujeres y, aunque no hay mucha documentación acerca de hombres que declaren ver telenovelas (por ser un género televisivo considerado para mujeres), nosotros registramos audiencias, si bien mayoritariamente del genero femenino, ciertamente con la participación de algunos del género masculino.

\section{Escenas}

Familia Olvera Nava

Primera llamada..

Un viernes de enero por la noche, entre la estancia y el comedor. Dolores, la madre, está en el comedor arreglando la ropa. Mariana y Paola están sentadas en la sala de la estancia viendo la televisión.

Dolores: Mariana ¿a qué hora es?

Humberto: Son las nueve y media.

Mariana: Mamá, no se preocupe, yo le aviso cuando sean las diez para que venga a ver su novela. (El Vuelo del Águila)

Paola: Mamá Dolores ¿es cierto lo que me dijo Mariana el otro día?

Dolores: ¿Qué te dijo?

Paola: Que esa novela te recuerda a mi abuelita Simonita.

Dolores: Sí, porque Simonita nos contaba que a ella le tocó vivir en esa época revolucionaria en su juventud y que por esos años conoció a Goyito (el esposo de Simonita) Cuando me casé con su papá, Simonita--por las tardes-- siempre me contaba la imagen que tenía del pueblo de Porfirio Diaz y de los caudillos. También me comentaba que a Goyito, por ese entonces, lo iban a fusilar, porque era carne y uña con Zapata y porque a la familia Alemán le despojó las inmensas tierras que tenian bajo su poder para repartirlas a los ejidatarios.

Mariana, dirigiéndose a Dolores: Véngase a sentar que ya va a comenzar la novela.

Dolores: (durante un comercial) Pero también recuerdo a mi mamá, pues asi como esos vestidos que salen en la comedia, ella nos mandaba hacerlos con Teofilita. 


\section{Valeria, recién llegada: ¿Y quién fue Teofilita?}

Dolores: Una viejecita que vivió muy sola, no tenia familiares en el pueblo. Ella decía que era de Monterrey y que allá estaban todos sus parientes, pero yo nunca supe que la visitara algún familiar ni cuándo murió. Pero después te cuento, déjame ver mi telenovela. Además, primero ve a saludar a tu papá que ya llegaste, si no en la noche va a empezar que llegas tarde y que él es al último que saludas.

Valeria: Si, ahorita voy, nadamás déjame acomodar mis cosas, para que Mariana no me empiece a regañar.

Segunda llamada..

Domingo 1 de enero, Miguel y Dolores están en su recámara.

Miguel: ¿Qué no les dolerá la cabeza y aburrirá tener todos los domingos la televisión prendida?

Dolores: Pues yo le he dicho que no vean tanta televisión porque se van a lastimar la vista, pero me toman de a loca.

Miguel: Valera dile a Humberto que si ya barrió la casa de su perro, o que si primero está la televisión y después ese pobre animal.

Valeria (desde el vestíbulo): Sí ya la barrió. Además es la condición que le puso usted para conservar al perro.

Miguel: Bueno, te pregunto porque tus hermanos, como se enlelan con la televisión el dia de hoy.

Valeria: No sea exagerado don Miguelito.

Miguel: Si yo tuviera su edad, es para que anduviera haciendo actividades que ayuden a la limpieza de la casa.

Valeria: Pero los chiquitos (hermanos más pequeños de la casa) trabajan toda la semana, y es justo que descansen un día.

Miguel: Pero no es todo el día. Además ellos gozan de mucha libertad, a comparación de la mía, cuando yo tenía su edad. Llegan a cualquier hora; no avisan adónde van y de qué te quejas si tú también llegas a cualquier hora de la noche, sin pedir permiso.

Humberto (entra a la recámara de sus padres): Ahorita vengo. No me tardo. Miguel: Si vas a salir, apagas la tele para que no se gaste la luz a lo menso.

Humberto. No. La voy a dejar prendida para que alguien escuche cómo quedó el partido. Además, no tarda en llegar Goyo (uno de los hermanos mayores) $Y$ él, aunque no esté viendo la tele, siempre la tiene prendida, según para que le haga compañia.

Miguel: Se quejan de su hermana y su mamá que se idiotizan viendo una telenovela, y con ustedes es lo mismo. 
Convergencia Revista de Ciencias Sociales, núm. 12/13, 1996, Universidad Autónoma del Estado de México

Humberto (saliendo de la recámara de sus papás): No es cierto porque los partidos nunca son los mismos. Me voy porque se me hace tarde.

\section{Tercera llamada..}

Son las 19: 00 horas, de la tercera semana de diciembre. En la estancia se encuentran los tres hermanos menores Y Paola, la sobrina

Guillermo: Paola, no le estés cambiando cada rato de canal. Humberto: No la regañes. Yo le dije que en cada comercial le pasara a otros canales, para saber si va a verpartidos de futbol.

Gerardo: Si va a ver un partido.

Guillermo: Ya sabes. Ahora que no le esté cambiando.

Paola: Ay Guillermo, tú cuando tienes el control de la tele decides quéprogramas se van a ver, y uno no te puede decir que lo cambies porque te enojas. Además, ahorita yo tengo el control y yo decido a qué canal le voy a cambiar. Si no te gusta que le esté cambiando, abi está la tele en su cuarto.

Guillermo: Esa tele no me gusta porque es a blanco y negro y la pantalla es chica. Miguel (que sale de su recámara): No estén peleando porque me apagan esa tele y no la van a ver en toda la semana.

Paola (entre dientes): Ya ven, hay que callarnos y ver la tele.

\subsubsection{Cuarta lectura}

Hope Jensen indica que nos podemos referir a la televisión como un "marcapasos" alrededor del cual se establecen otras actividades. (Jensen, 1985) Observamos cómo a través de la escena captada, una telenovela acota el cambio de actividades en miembros de la familia. Esta situación parece reflejar una constante en familias de varios países, por ejemplo, en Estados Unidos de Norteamérica. (Leichter et. al, 1985); en China. (Lull, 1990); en Venezuela. (Barrios, 1992); en Chile. (Fuenzalida, 1992); en Colombia. (Segura, 1992) y en México. (Renero, 1992)

Más adelante, en la misma escena, el contenido que presentaba la telenovela "El Vuelo del Águila" interpela de manera particular a Dolores, la mujer de mayor edad de la familia manifiesta y entreteje su propia historia personal con las imágenes y contenido de la telenovela. Se desgrana en la escena familiar un discurso y convoca parte de la vida de Dolores y la socializa con otros miembros que en ese momento constituyen una sub-audiencia del resto de la estructura familiar. 
Dolores detiene su relato, decide suspenderlo porque en ese momento privilegia el discurso de la telenovela y --entre anuncios-- continúa. No podríamos aceptar en esta escena familiar que la televisión interrumpe la comunicación familiar pues antes la ha desencadenado y construye un puente facilitado por los anuncios para dar cauce al resto del relato. También parece que abre espacios para ventilar la identidad de Dolores, en esta estructura y dinámica familiar.

En la segunda escena, Miguel y Dolores, estaban escuchando la radio. La interacción con la televisión es más selectiva y esporádica que el resto de los miembros de familia. La valoración que Miguel expresa respecto del tiempo frente al televisor deja ver el intento de establecer una regla que no se ha logrado instaurar: mirar poco tiempo el televisor, es decir, hay reglas familiares y valoraciones que flotan en los discursos de los padres pero que no logran su concreción. También se puede ver cómo esa valoración expresada por Miguel fue codificada con un término proporcionado por la misma televisión; cuando el padre de familia señala que sus hijos "se enlelan con la televisión invoca el nombre de una sección del añejo programa televisivo de "Los Polivoces", denominada "Los Hermanos Lelos", dos personajes que parecían retrasados mentales y sus conductas eran estúpidas. El resto de los miembros de familia decodifican con la misma acepción debido a que comparten parte de la historia familiar y televisiva.

Finalmente emerge otra vez el asunto del control remoto. Esta nueva tecnología peri-televisiva configura un nueva manera de desplazamiento del poder. Ejerce control quien gana el dispositivo para cambiar a distancia de canal. En escena Paola tiene el control, pero Guillermo, en otro momento, ha tenido el control remoto y por lo tanto el poder para decidir qué ver y cómo interactuar con la televisión implicando al resto de la audiencia. Pero ese poder es sujeto a una regla más general instaurada en la familia: la regla que reza en esta familia no debe haber riña entre sus miembros a causa de la selección de canales

\section{Conclusiones}

1. Documentar a las familias en términos de estructura, dinámica familiar, equipamiento cultural doméstico, espacio habitacional, rutinas, trayectoria educativa y laboral permite contar con elementos que contribuyen a entender y contextualizar los procesos virtuales o tácitos de interacción con la televisión. 
2. La estructura y dinámica de las familias constituyen referentes importantes para orientar preguntas de investigación acerca de la interacción con la televisión y otras tecnologías que conforman el escenario familiar.

3. Pese a la disponibilidad de aparatos de televisión (más de uno en cada caso) y de espacios físicos distintos, las familias definen territorios para la interacción televisiva en los que se manifiestan los pliegues y repliegues del poder que cada uno de ellos tiene.

4. Las rutinas de los miembros de las familias no sólo explican las pautas de interacción televisiva sino que permiten trazar las posibilidades que cada uno tiene para ocupar territorios y tiempos con la televisión.

5. El contenido televisivo convoca e interpela diferencialmente a los miembros de la familia de acuerdo con la historia de cada uno, género, generación, rutina y ubicación jerárquica que ocupa dentro de la familia.

6. Los momentos y formas de interacción televisiva están demarcados potencialmente por las rutinas de cada miembro pero también son una función de la dinámica construida históricamente en el núcleo familiar.

7. El control remoto es un dispositivo peri-televisivo que ha configurado nuevas formas de interacción con la televisión; también parece amalgamar inéditas pautas interactivas entre los miembros de la familia y se ha convertido en un nodo que puede reflejar la configuración diferencial del poder en el núcleo familiar.

\section{Bibliografia}

Andolfi, Maurizio, 1985: Terapia Familiar, México: Paidós

Barrios, Leoncio, 1992: Familia y Televisión, Venezuela: Monte Avila Editores Latinoamericana.

Barrios, Leoncio, 1992: “Televisión, comunicación y aprendizaje en el contexto de la familia. Estudio etnográfico realizado en Venezuela” en: Orozco, Guillermo. , Comp: Hablan los Televidentes. Estudios de Recepción en Varios Paises. Cuadernos de Comunicación y Prácticas Sociales No. 4., México: UIA.

Bowen, Murray, 1978: Family Therapy in Clinical Practice. Nueva York: Jason Aronson.

Cornejo Portugal, Inés, 1994: ¿Cómo la ves? El psicodrama aplicado para el estudio de la recepción televisiva de los niños. En Televidencia Perspectivas para el análisis de los procesos de recepción televisiva. Cuadernos de Comunicación y Prácticas Sociales, Núm. 6, México: Iberoamericana. 
Cusinato, Mario, 1992: Psicología de las Relaciones Familiares, Barcelona: Herder.

Fuenzalida, Valerio, 1992:" ¿Qué Ven los Campesinos Chilenos en la Telenovela? Del reconocimiento a la reivindicación del televidente" en: Orozco, Guillermo., Comp: Hablan los Televidentes. Estudios de Recepción en Varios Paises Cuadernos de Comunicación y Prácticas Sociales No. 4., México: UIA.

Foucault, Michel, 1979: Microfísica del Poder Barcelona: La Piqueta Giddens, Anthony, 1991: Sociología, Madrid: Alianza Universidad.

González, Jorge, 1993: "La cofradía de las emociones in/terminables. Telenovela, memoria, familia” En: García Canclini, Néstor. El Consumo Cultural en México. México: CONACUL TA.

Goodman, Irene, 1983: “TV's Role in Family Interaction” en: Journal Of Family Issues, Vol. 4, Núm. 2.

Gray, A., 1987: "Behind closed doors: Video recorders in the home" En: H Baerh \& G. Dyer., Eds, basado en: Women And Television, London: Pandora, Eds

Hobson, D. Crossroads, 1982: The Drama Of As Soap Opera. London: Methuen, Eds.

Hoffman, Lynn, 1987: Fundamentos de la Terapia Familiar. Un marco conceptual para el cambio de sistemas, México: FCE.

Jensen, Hope. et. al., 1985: "Family contexts of television" en: ECTJ. Vol 33, No.

Leichter, H el. al., 1985: "Family Contexts of Television" en: Educational Communication And Technology Journal. No. 33.

Lull, James, 1980: "The social uses of television" en: Human Communication Research. Vol. 6, No. 3.

Lull, James: "Recepción televisiva, reforma y resistencia en China. Un estudio etnográfico". En Hablan los Televidentes. Estudios de Recepción en Varios Paises. Cuadernos de Comunicación y Prácticas Sociales No. 4., México: UIA

Lull, James, 1990: Inside Family Viewing. Ethnographic Research on Television's Audiences. London and New York: Routledge, Eds.

McGoldrick, Monica y Randy Gerson, 1990: Genogramas en la Evaluación Familiar, Barcelona: Gedisa.

Michel, Andrée, 1974: Sociología de la Familia y del Matrimonio. Barcelona: Península.

Minuchin, Salvador, 1994: Familias y Terapia Familiar. Barcelona: Gedisa. 
Munuchin, S y Fischman, H. Ch., 1993: Técnicas de Terapia Familiar. México: Paidós.

Orozco, Guillermo, 1992: "Familia, televisión y educación en México. La teoría educativa de la madre como mediación en la recepción televisiva de los niños En Hablan los Televidentes. Estudios de Recepción en Varios Paises Cuadernos de Comunicación y Prácticas Sociales No. 4., México: UIA.

Renero Quintanar, Martha, 1992: "La mediación familiar en la construcción de la audiencia. Prácticas de control materno en la recepción "televisiva" infantil" en: Orozco, Guillermo, Hablan los Televidentes. Estudios de Recepción en Varios Paises. Cuadernos de Comunicación y Prácticas Sociales No. 4., México: UIA.

Segura Escobar, Nora, 1992: “Usos sociales de la televisión y de la telenovela. La Familia frente a la televisión: Hábitos y rutinas de consumo en Cali” en: Martín-Barbero, Jesús y Sonia Muñoz, Coord.: Televisión y Melodrama Colombia, Tercer Mundo Editores.

Taylor, S y R. Bogdan, 1984: Introducción a los Métodos Cualitativos de Investigación. México: Paidós. 


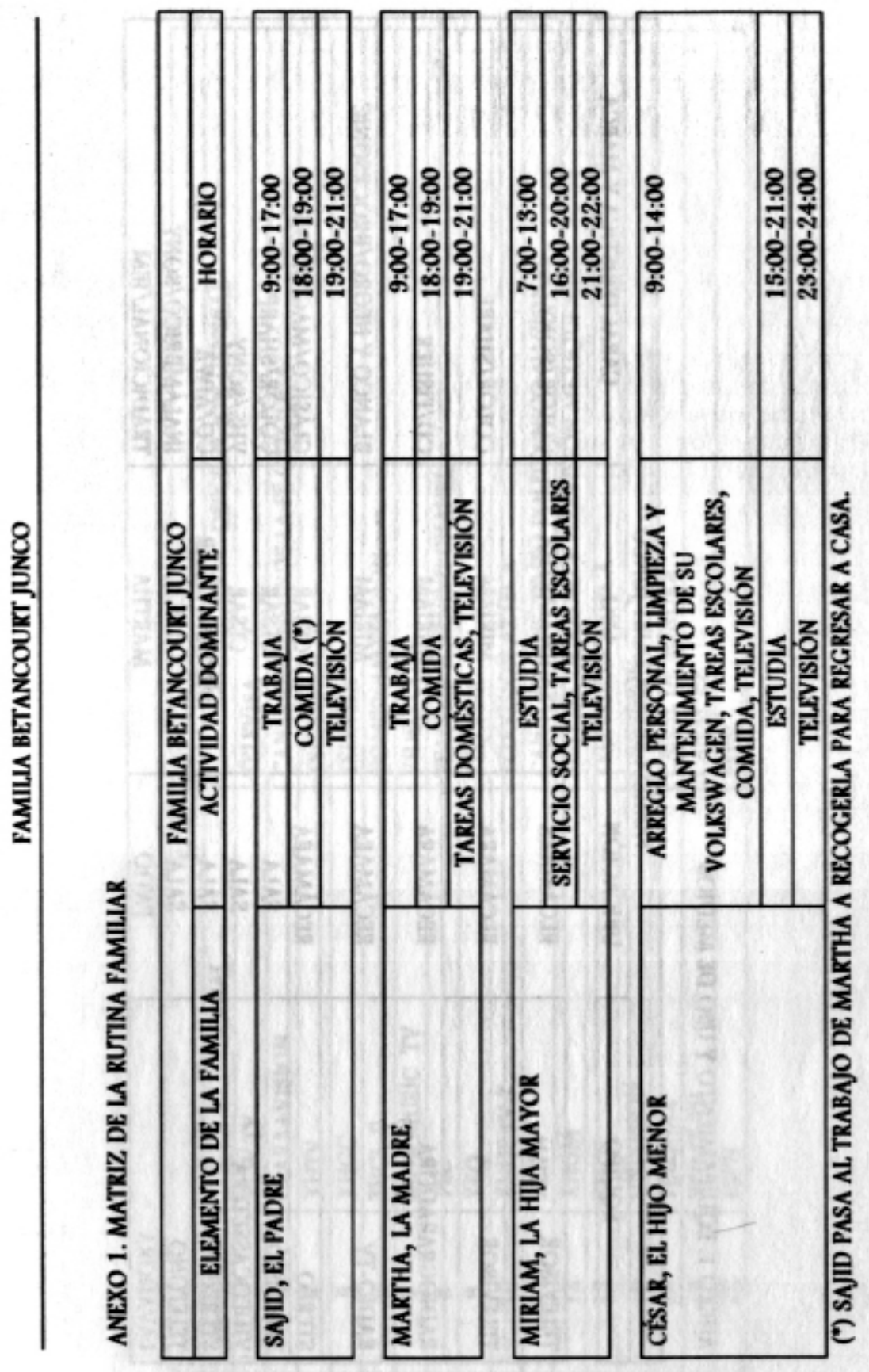


Convergencia Revista de Ciencias Sociales, núm. 12/13, 1996, Universidad Autónoma del Estado de México

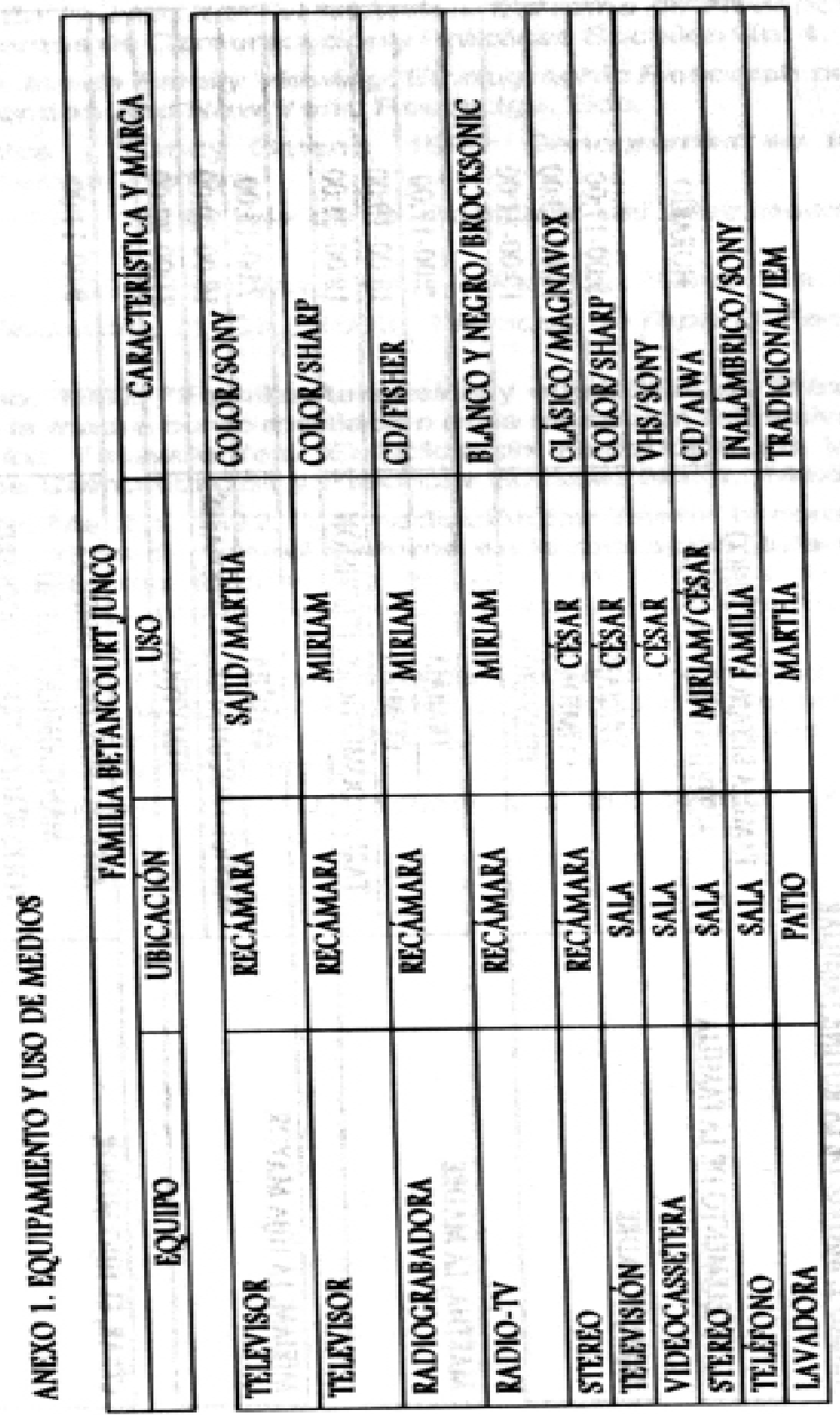




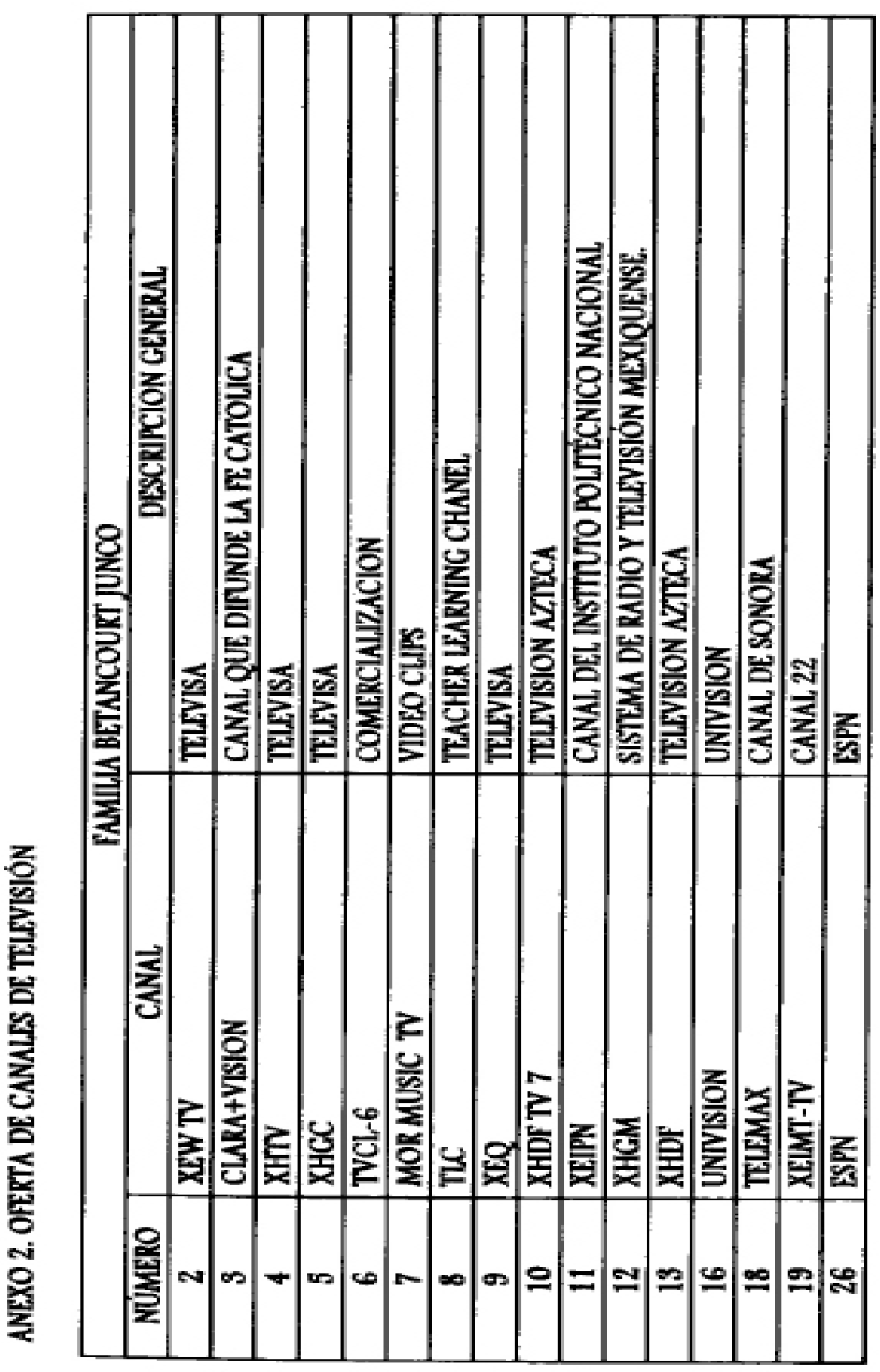


Convergencia Revista de Ciencias Sociales, núm. 12/13, 1996, Universidad Autónoma del Estado de México

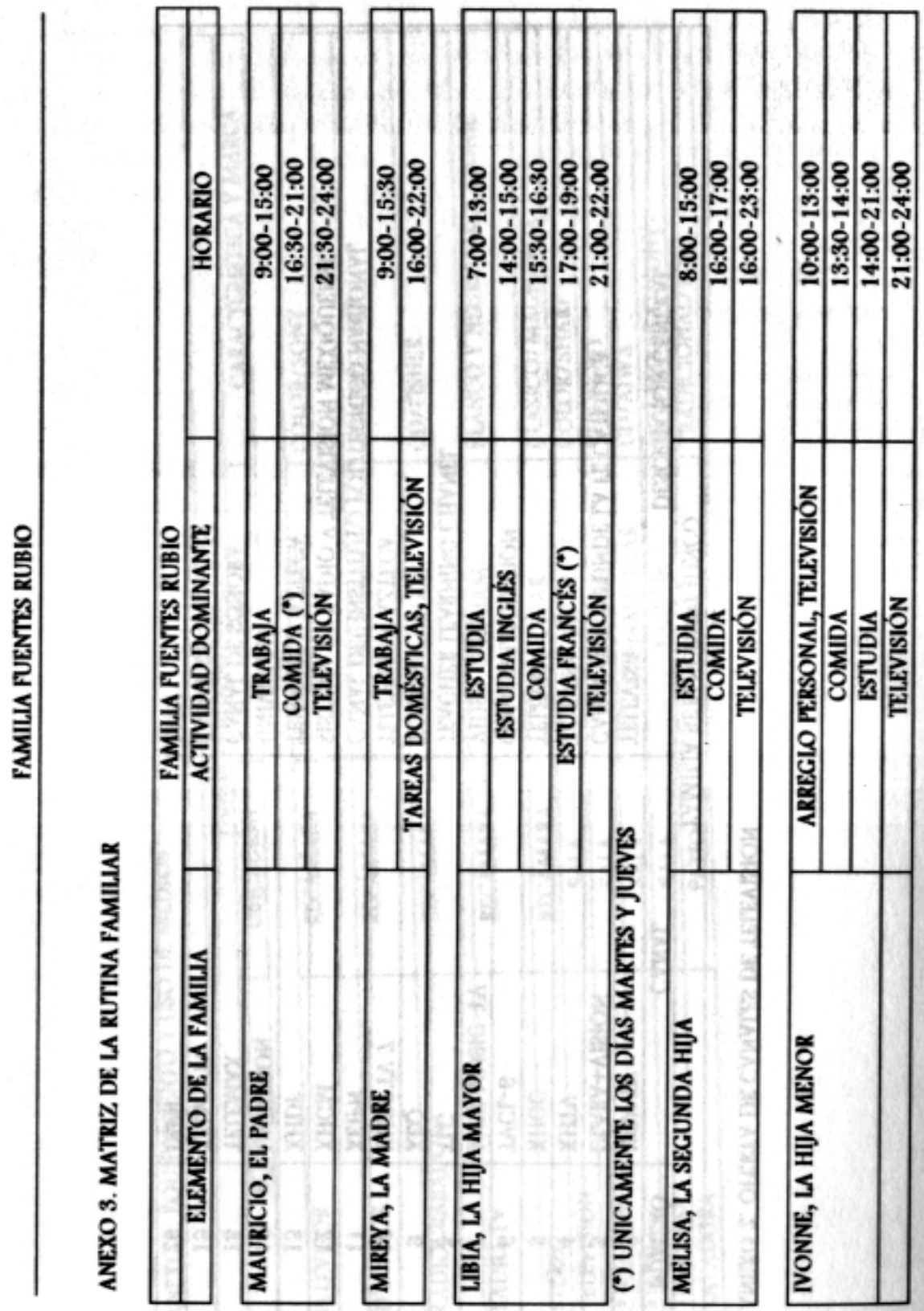




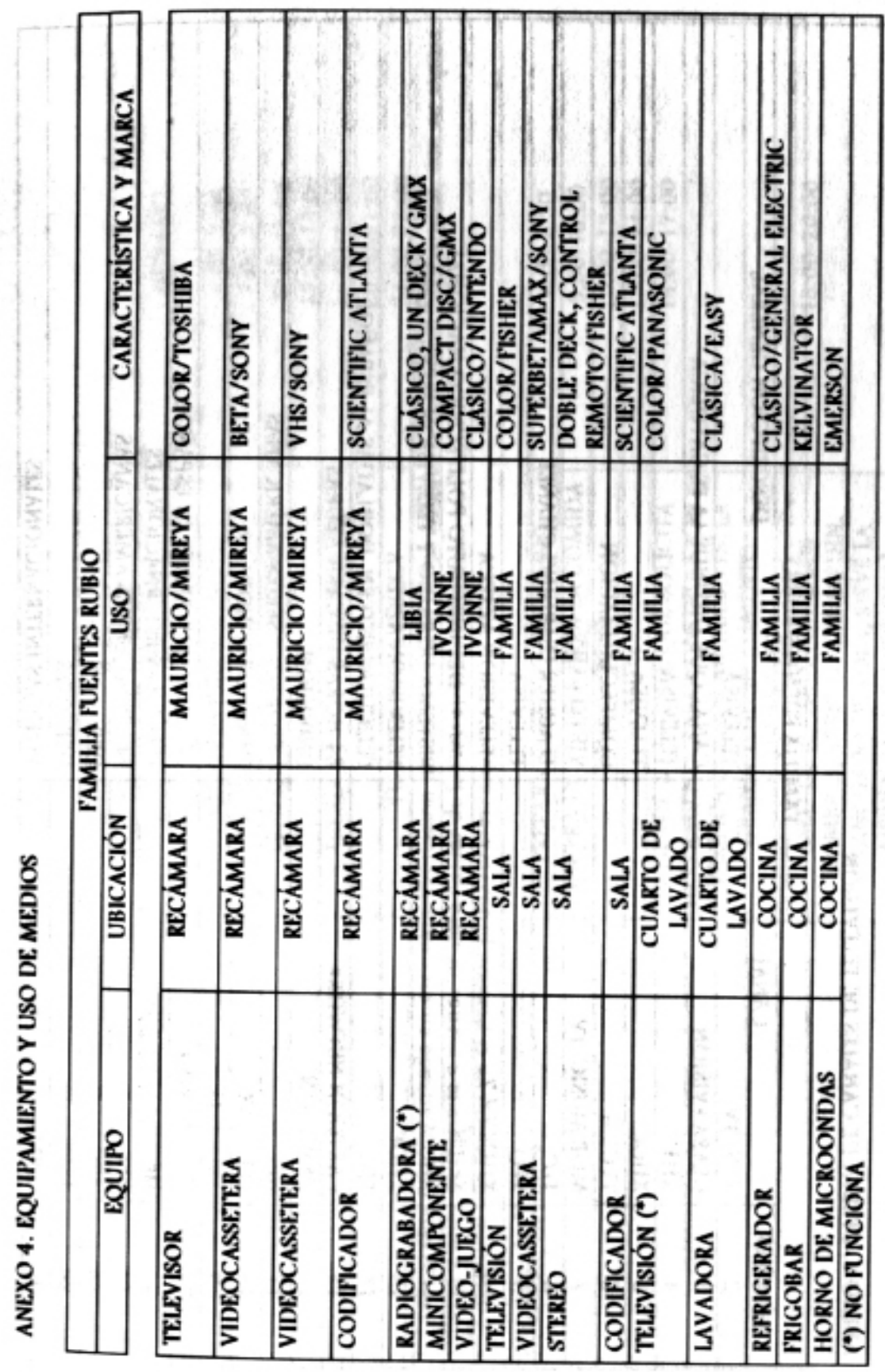


Convergencia Revista de Ciencias Sociales, núm. 12/13, 1996, Universidad Autónoma del Estado de México

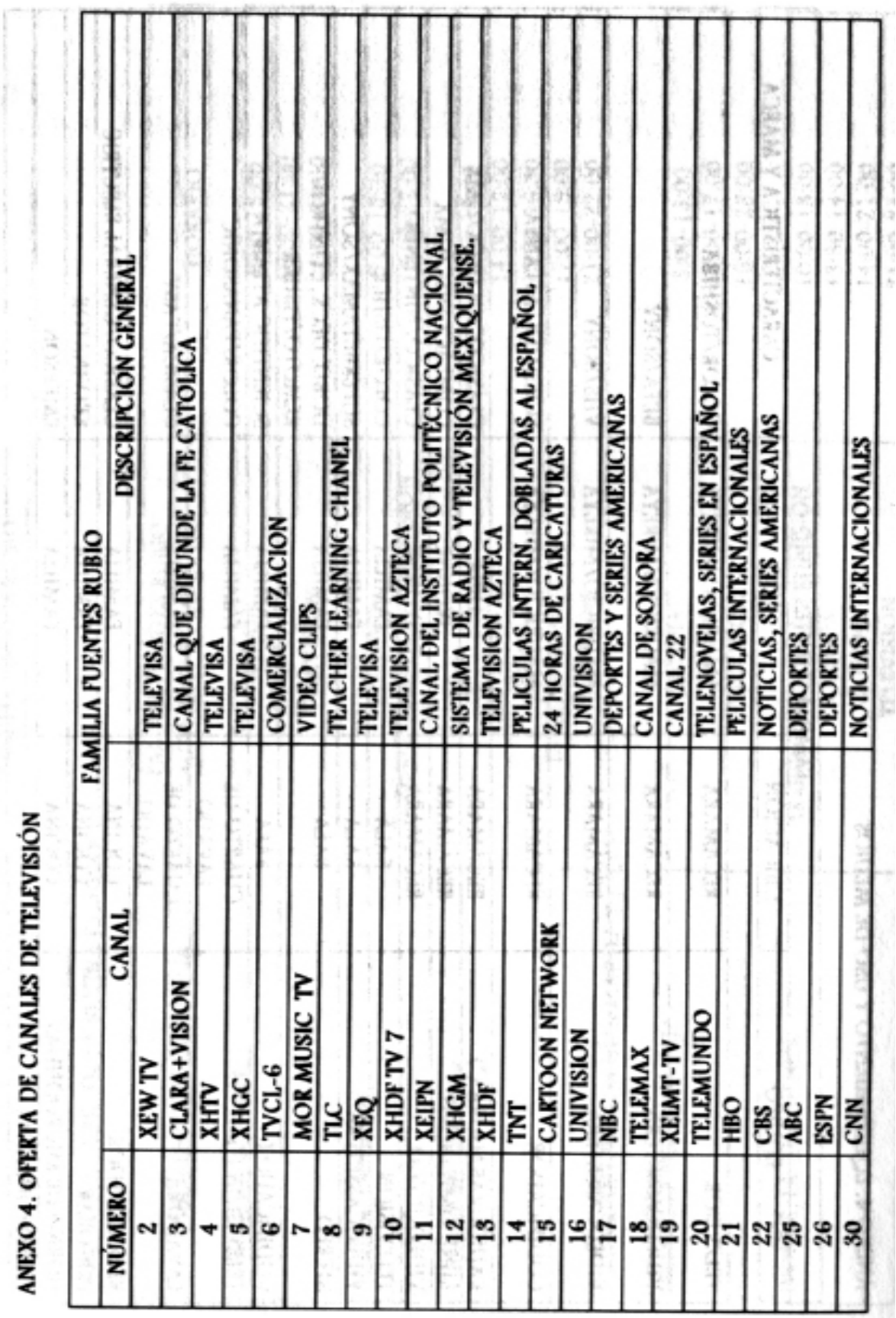




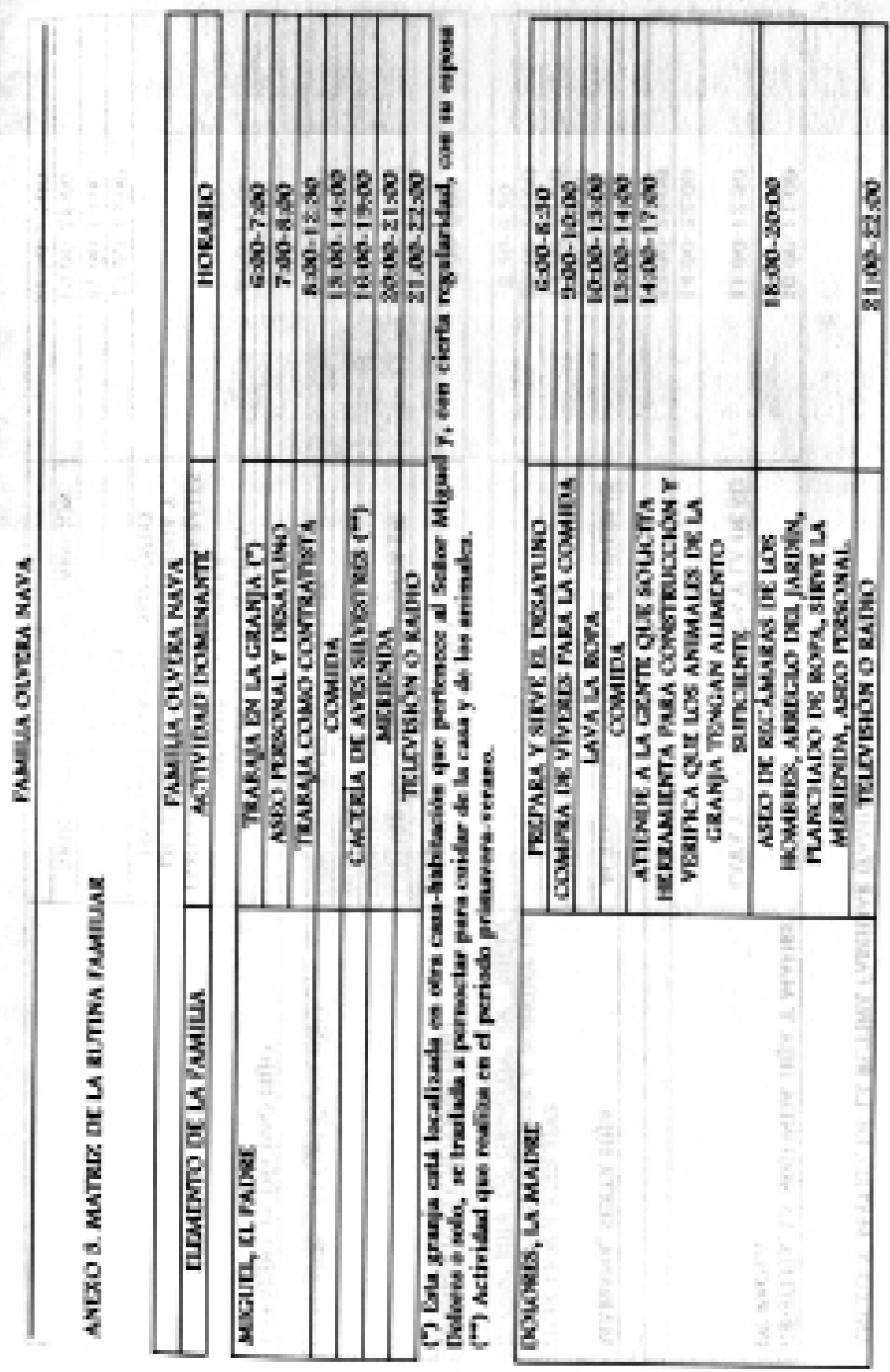


Convergencia Revista de Ciencias Sociales, núm. 12/13, 1996, Universidad Autónoma del Estado de México
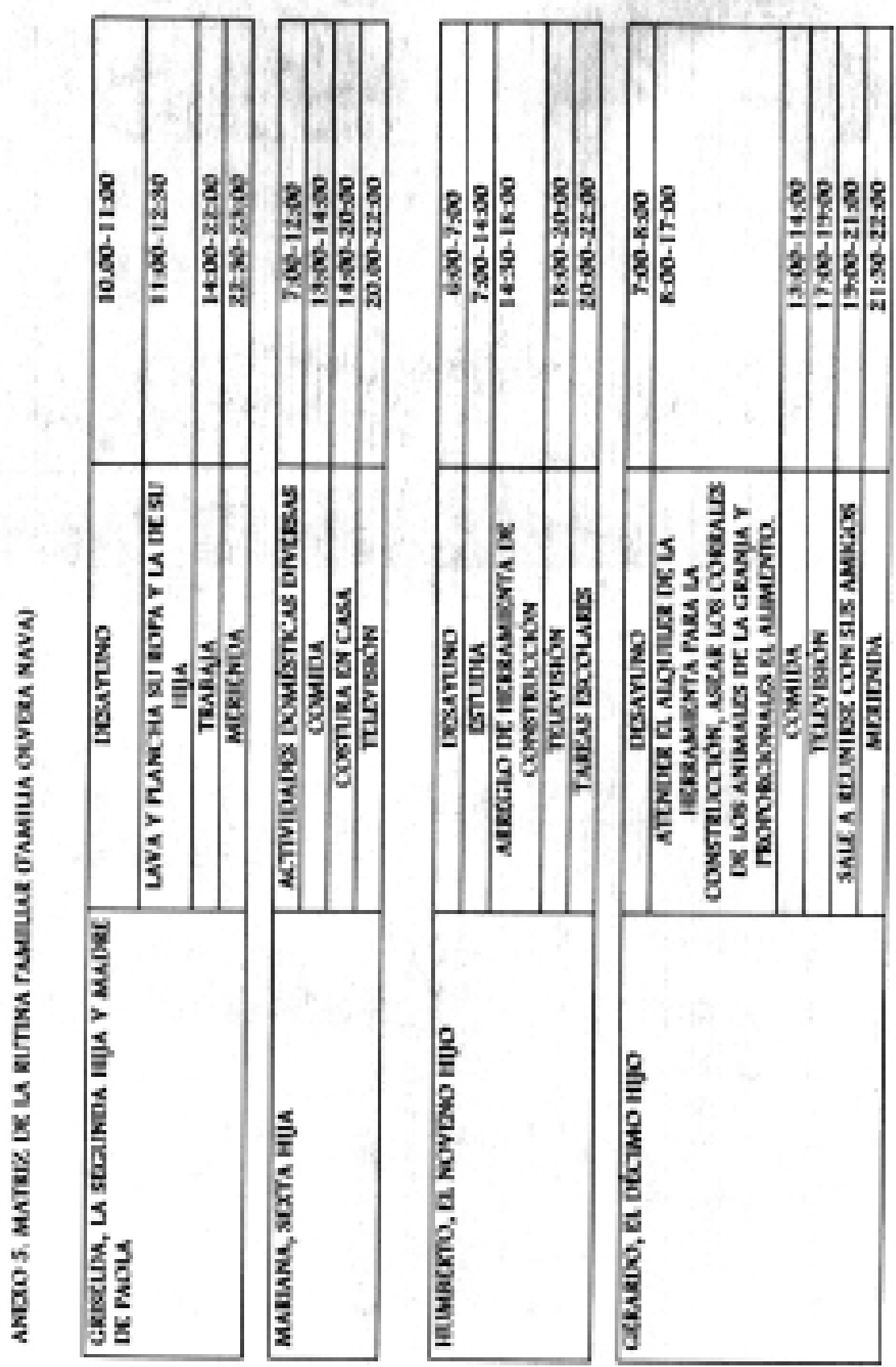

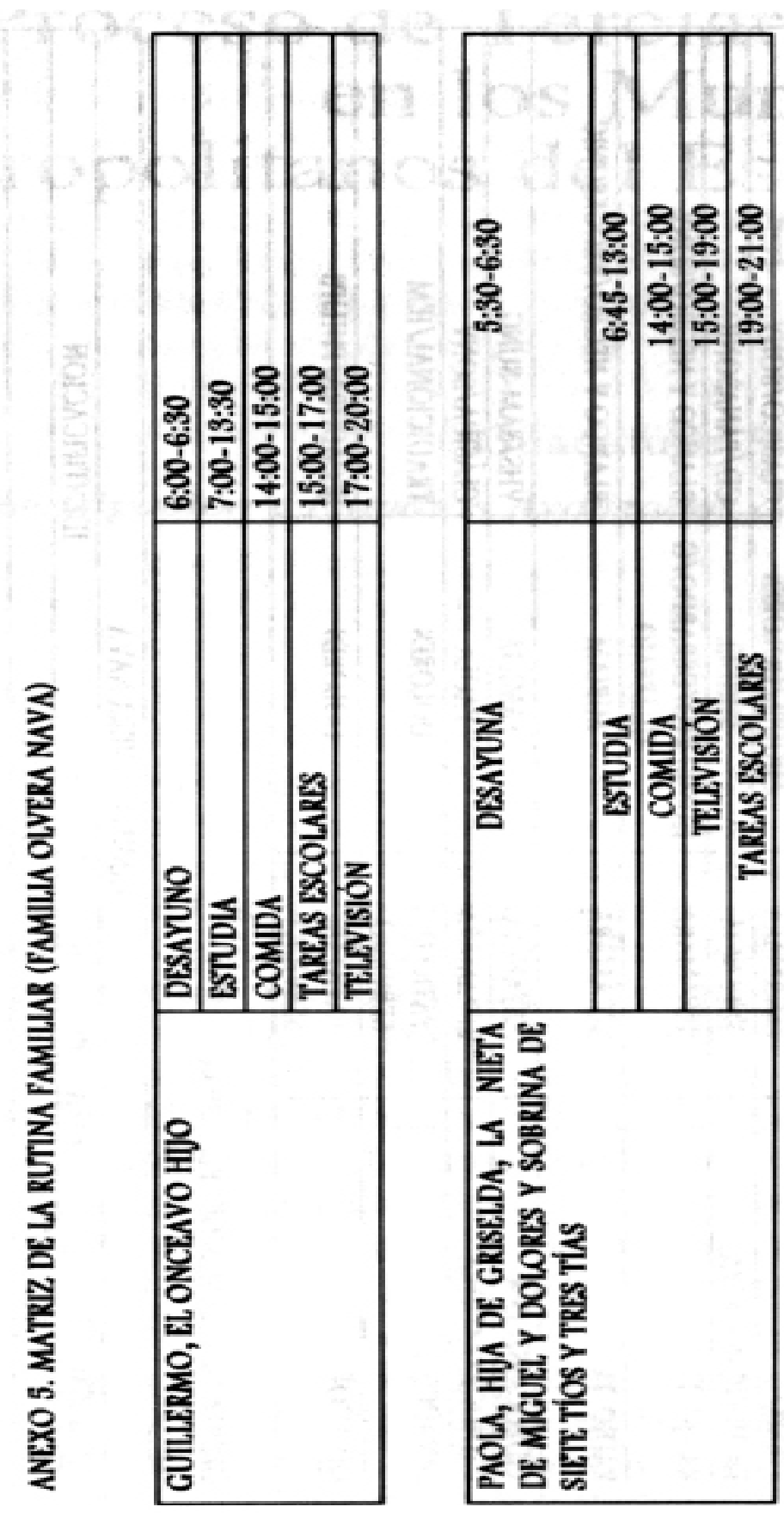
Convergencia Revista de Ciencias Sociales, núm. 12/13, 1996, Universidad Autónoma del Estado de México
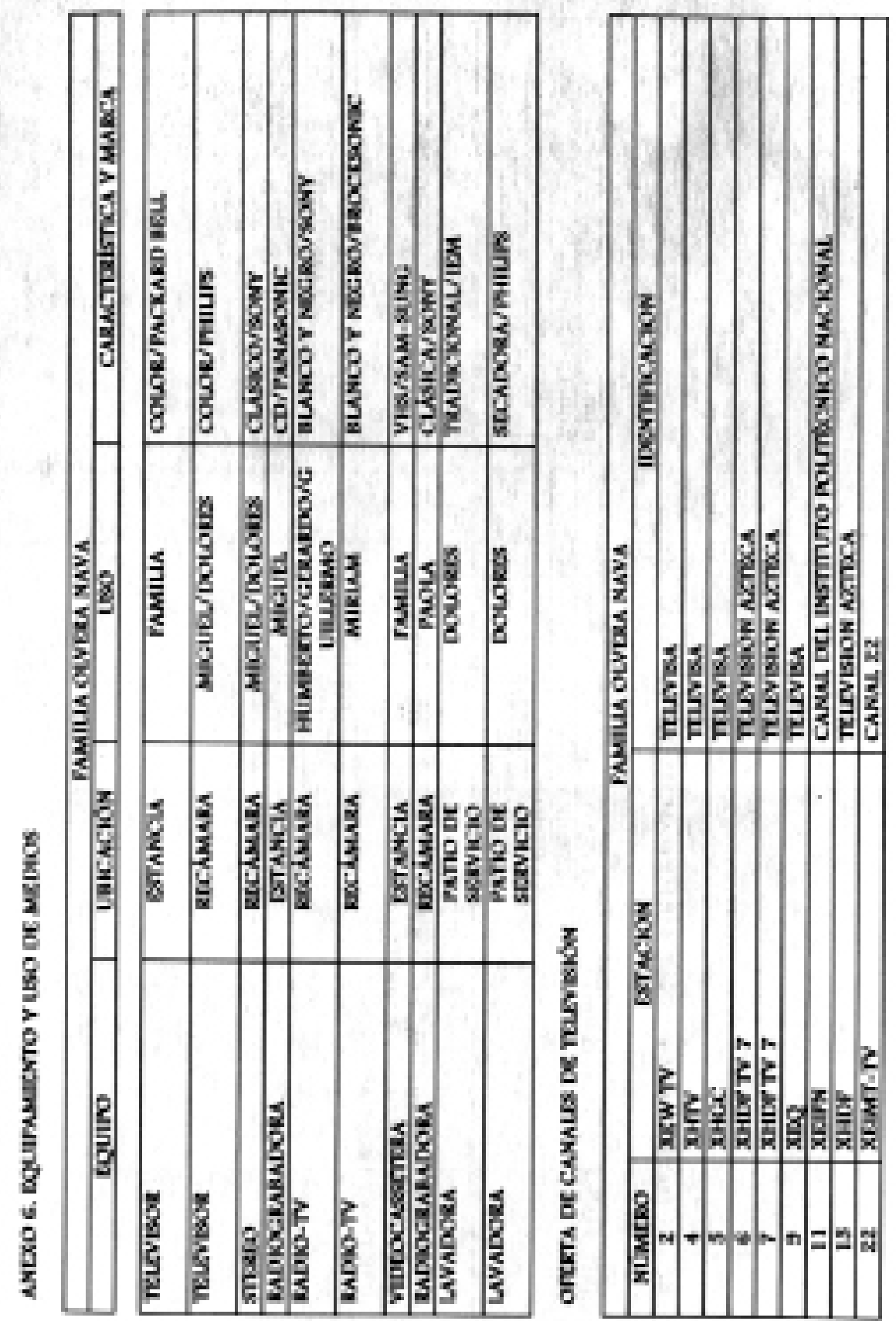